\title{
Progress toward a non-viral gene therapy protocol for the treatment of anemia
}

\author{
Magdolna G. Sebestyén ${ }^{1}$, Julia O. Hegge ${ }^{1}$, Mark A. Noble ${ }^{1}$, David L. Lewis ${ }^{1}$, Hans \\ Herweijer $^{1}$, and Jon A. Wolff ${ }^{2}$ \\ 1 Mirus Bio Corporation, Madison, WI 53719 \\ 2 University of Wisconsin-Madison, Departments of Pediatrics and Medical Genetics, Madison, WI 53705
}

\section{Abstract}

Anemia frequently accompanies chronic diseases such as progressive renal failure, AIDS and cancer. Patients are currently treated with erythropoietin (EPO) replacement therapy using various recombinant human EPO protein formulations. Although this treatment is effective, gene therapy could be more economical and more convenient for the long-term management of the disease. The objective of this study was to develop a naked DNA-based gene therapy protocol that could fill this need. The hydrodynamic limb vein technology has been shown to be an effective and safe procedure for delivering naked plasmid DNA (pDNA) into the skeletal muscles of the limb. Using this method, we addressed the major challenge of an EPO-based gene therapy of anemia: maintaining stable, longterm expression at a level that sufficiently promotes erythropoiesis without leading to polycythemia. The results of our study using a rat anemia model provide proof of principle that repeated delivery of small pDNA doses has an additive effect and can gradually lead to the correction of anemia without triggering excessive hemopoiesis. This simple method provides an alternative approach for regulating EPO expression. EPO expression was also proportional to the injected pDNA dose in nonhuman primates. In addition, long-term (over 450 days) expression was obtained after delivering rhesus EPO cDNA under the transcriptional control of the muscle-specific MCK promoter. In conclusion, these data suggest that the repeated delivery of small doses of EPO expressing pDNA into skeletal muscle is a promising, clinically viable approach to alleviate the symptoms of anemia.

Overview summary-We delivered various EPO-expressing naked pDNA constructs into the skeletal muscles of the limb by the minimally invasive, hydrodynamic limb vein (HLV) procedure. Serum EPO concentrations and the physiological response were pDNA dose-dependent both in rats and rhesus monkeys. The kinetics and longevity of expression were promoter-dependent. The mouse MCK promoter provided stable expression for well over a year, while the effect of the CMV promoter construct lasted only for 5-7 months. By using repeated, small-dose pDNA injections in a rat anemia model, EPO expression was controlled at the most fundamental level of the delivered gene dose. Our results suggest that this non-viral gene therapy approach provides safe and long-term solution for the treatment of chronic anemia and that it can be tailored to the individual needs of the patient.

\section{Introduction}

Erythropoietin (EPO) plays a central role in the regulation of red blood cell production by controlling the proliferation, differentiation and survival of erythroid progenitors in the bone marrow. Patients suffering from various chronic diseases, such as progressive kidney failure, AIDS or cancer, often develop anemia that affects their quality of life and their chances for

Corresponding author: Magdolna G. Sebestyén, Mirus Bio Corporation, 505 S. Rosa Rd. Suite \#104, Madison, WI 53719, USA, Phone (608)-441-2868, Email: Magdi.Sebestyen@MirusBio.com.

Jon A. Wolff has a financial interest in Mirus Bio Corporation. 
survival (Weiss and Goodnough, 2005). Even the otherwise healthy elderly can develop anemia contributing to progressive impairment (predominantly weakness and constant fatigue) and untimely death (Ble et al., 2005). Cumulatively, the disease affects millions in the United States alone. Most of these patients are currently treated by EPO replacement therapy involving the injection of recombinant human EPO protein with a frequency of three times a week up to only once in every 2-4 weeks, depending on the formulation of the drug. Although this therapy is effective, it is expensive and the repeated injections are inconvenient. In addition, the protein products require refrigeration and sterile injection supplies, which make this treatment option less available for certain geographical regions, such as AIDS-plagued Africa. Furthermore, repeated subcutaneous injections can lead to skin irritation and occasionally to an immune response against human EPO leading to autoimmune pure red-cell aplasia (Boven et al., 2005). These factors have triggered intensive research efforts for a more permanent and more economical solution: EPO-based gene therapy.

Serum proteins such as EPO can be produced and secreted into the blood stream by delivering their genes to ectopic sites. In adults EPO is normally produced only by the peritubular interstitial cells of the kidney (Fisher, 2003). Yet, liver and skeletal muscle can also synthesize and secrete EPO, if the gene is delivered under the transcriptional control of an appropriate promoter (our own unpublished data and Tripathy et al., 1996; Fattori et al., 2005; Rivera et al., 2005). Other sites, such as airway epithelia, the eye, salivary glands and skin have also been shown to be capable of producing and secreting EPO (Maruyama et al., 2001b; Auricchio et al., 2002; Davis et al., 2004; Wang et al., 2006). Since the overexpression of EPO leads to polycythemia, which can cause serious health problems, controlling serum EPO levels after gene delivery has been the focus of most EPO-based gene therapy research. Several regulatable expression systems have been developed to permit transcription only in the presence of a smallmolecule ligand such as mifepristone (Nordstrom, 2003), doxycyclin (Lamartina et al., 2002; Chenuaud et al., 2004b) or the "dimerizer" agent, rapamycin (Rivera et al., 2005). All these approaches involve the long-term administration of a drug that may have side effects. Perhaps even more problematic is that they utilize chimeric transactivators to regulate transcription, which may elicit an immune response resulting in the rejection of all expressing cells (Favre et al., 2002; Latta-Mahieu et al., 2002). A safer and more promising alternative tested in animals involves controlling EPO expression via a hypoxia response element in the enhancer (Binley et al., 2002). However, due to the complexity of the mechanisms that normally regulate physiological EPO expression, mimicking them may be quite challenging. Although dramatic progress has been made in this field in the past 5-10 years, the clinical relevance of regulatable expression systems remains to be demonstrated (reviewed in Goverdhana et al., 2005).

All the above approaches are based on the delivery of an excessively high copy number of the transgene followed by the regulation of transcription. It is our hypothesis that controlling the amount of gene product at the level of the delivered gene dose itself would be a simpler and more fundamental option. Within a certain range, an increase in the copy number of expression vector delivered into cells or an increase in the number of transfected cells will lead to higher transgene expression levels. One of the major goals of these studies was to obtain proof of concept that a simple approach of repeatedly injecting small pDNA doses is suitable to establish and maintain the desired level of EPO expression and erythropoiesis.

The gene delivery method plays a key role in the success of this approach. Controlling gene expression at the administered gene dose requires the ability to perform multiple deliveries as indicated by the patient's response. Due to the immunogenicity of viral coat proteins, repeated deliveries of viral vectors are ineffective. For the delivery of non-immunogenic naked pDNA we have developed a simple, yet effective technique, the hydrodynamic limb vein (HLV, trademarked as Pathway $I V^{\mathrm{TM}}$ ) procedure (Hagstrom et al., 2004). It involves the rapid injection of a large volume of DNA-containing fluid through a peripheral vein into a limb that is 
temporarily isolated from normal blood flow by a tourniquet. Veins are easily accessible through the skin and they provide direct conduit to all muscle groups of the limb. The injections are performed in an anterograde direction (i.e., with the blood flow) to avoid complications from injecting against the valves of the venous system. While there have been some concerns raised about the safety of the procedure due to the delivered volume, the injection rate and the use of a tourniquet, they are not supported by the large body of data collected in mice, rats, dogs and non-human primates. We have shown in rats that the edema caused by the injected fluid is resolved within 24 hours and that even the minimal signs of observed muscle toxicity clear within 2 weeks post-injection (Toumi et al., 2006). Using magnetic resonance imaging monitoring and contrast-enhanced 3D magnetic resonance angiography in rhesus monkeys, we have also determined that the effects of the procedure on the arterial and venous vascular systems, and on the intra-muscular compartments, are transient and conditions return to normal within 3 days (manuscript submitted to Human Gene Therapy). Furthermore, tourniquets are commonly used in the clinic for local anesthesia during distal limb surgery (e.g., the Bier block for carpal tunnel repair) and the resulting ischemia is well tolerated by the muscle for hours, while our procedure takes only a few minutes. Thus, all the animal studies and current clinical experience with tourniquets suggest that in a clinical setting the HLV procedure will become a quick, simple and safe outpatient procedure. Based on successful pre-clinical studies using the $m d x$ mouse and Golden Retriever dog models of Duchenne muscular dystropy, we (in collaboration with Transgene, France) plan to test the procedure in a human clinical trial for delivering naked pDNA encoding human dystrophin into the forearm of Duchenne patients. One of the objectives of these studies was to adjust and optimize this procedure for the repeated delivery of small doses of the EPO gene into limb muscles. Using $\beta$-galactosidase and luciferase reporter genes we have earlier demonstrated that repeated HLV injections are possible, they are well tolerated and they lead both to an increasing number of expressing myofibers and to an increasing total amount of gene product (Hagstrom et al., 2004).

The other characteristic of transgene expression in skeletal muscle that is vital for the success of EPO-based gene therapy is stable, long-term expression. Episomal pDNA has been shown to persist in post-mitotic nuclei of myofibers for years after direct IM injections (Wolff et al., 1992). As a result, using a promoter that is not silenced, proteins can be produced in myofibers for years, as long as they do not elicit a cellular immune response, which would eliminate the expressing myofibers. For example, mouse dystrophin has been expressed in the myofibers of $m d x$ mice for at least 6 months after intra-arterial delivery (Zhang et al., 2004) and the mouse homologue of human placental secreted alkaline phosphatase (MUSEAP) has been expressed in mice for over a year, both after electroporation-enhanced muscle injections (Wang et al., 2001) and after HLV delivery (our unpublished results). The long-term expression of endogenous EPO in skeletal muscle has also been observed in several species using various delivery methods and promoters (Tripathy et al., 1996; Rizzuto et al., 2000; Rivera et al., 2005).

One of the major objectives of the present study was to use HLV pDNA delivery to test the feasibility of controlling EPO gene expression at the level of gene dose. This was assessed in a rat anemia model. The other goals were to assess the pDNA dose-dependence and the longevity of EPO expression in the limb muscles of non-human primates using constitutive and muscle-specific promoters. We demonstrate that the repeated administration of small pDNA doses by HLV delivery can trigger the desired level of red blood cell production and thus provides a promising clinical approach for the long-term management of chronic anemia. 


\section{Materials and Methods}

Plasmid DNA constructs

All the plasmids had a common backbone containing the Kanamycin resistance gene and its promoter from Tn5 and a ColE1 origin of replication. The CMV-RhEPO plasmid contained the full-length immediate/early promoter and enhancer region of human cytomegalovirus (CMV) corresponding to region -734 to +7 relative to the transcription start site (GenBank Accession number AY315197). Downstream from the promoter, the expression cassette contained a $\beta$-globin-IgG hybrid intron followed by the rhesus EPO cDNA coding region and the SV40 late polyA signal. The mMCK-RhEPO vector contained the full-length mouse muscle creatine kinase (mMCK) promoter and enhancer corresponding to positions -3351 to +7 from the transcription start site (GenBank Accession number AF188002) in place of the CMV promoter. In hMCK-RhEPO, the mMCK promoter was replaced by the human muscle creatine kinase (hMCK) promoter corresponding to nucleotides -2628 to +49 (GenBank Accession number M21487, Locus HUMCKMM1). The mMCK-ratEPO construct was identical to mMCK-RhEPO except for the coding region that was replaced by the rat EPO cDNA. The Empty-mMCK control vector contained the mMCK promoter in the same backbone without any coding region. Endotoxin-free pDNA was prepared by Aldevron (Fargo, ND, USA).

\section{Naked pDNA delivery into rat skeletal muscle}

All animal procedures were performed in compliance with protocols approved by the IACUC. The procedure for hydrodynamic limb vein injections in rats has been described (Hagstrom et al., 2004). Briefly, adult male or female Lewis rats between 180-300 gram body weight (Harlan, Indianapolis, IN, USA) were anesthetized with isoflurane (1-2\%). A latex tourniquet was wrapped around the upper hind limb to block blood flow. The distal great saphenous vein was exposed by a small incision, a 25-gauge catheter was inserted and a programmable syringe pump (Model PHD 2000, Harvard Apparatus, Holliston, MA, USA) was used to inject the pDNA-containing normal saline solution (NSS) at a rate of $10 \mathrm{ml} /$ minute. After injection, bleeding was controlled by light pressure and the incision was closed with suture. pDNA doses and injection volumes varied in the experiments as described in the results section.

\section{Disease model for anemia in rats using sub-total nephrectomy}

Adult (10 weeks old) male Lewis rats were bled before any treatment to establish a baseline for their blood chemistry values and hematological parameters. A two-stage surgical procedure was then followed to mimic kidney failure (Anagnostou et al., 1976). To perform the first, partial (2/3) nephrectomy, the animals were anesthetized using isoflurane (1-2\%) and a flank incision was made on the left side of the abdomen. The capsule of the left kidney was removed and the upper and lower poles were resected, leaving the pelvis and the hilum intact. Bleeding was controlled by the application of gelatin sponges (Gelfoam, Upjohn Inc., Kalamazoo, MI, USA). The animals were allowed to recover for one week, and then a second surgery was performed on the right kidney. The kidney was decapsulated, the renal artery, vein and ureter were ligated and the whole mass of the right kidney was removed. After both surgical procedures the abdominal muscles and skin were closed with Dexon suture. As a result of this two-step surgical procedure approximately $5 / 6$ of the total kidney tissue was removed. Sham operated animals went through the same 2-step procedure, but only the kidney capsules were removed while both kidneys were left intact. Pain was controlled by $1 \mathrm{mg} / \mathrm{ml}$ acetaminophen in the animals' drinking water.

All animals were allowed to recuperate for 6 weeks receiving a special diet supplemented with palatable baby- and cat-food and Nutri-Cal. All sham-operated animals survived the procedures and only $10 \%$ of animals with $5 / 6$ nephrectomy died or were euthanized due to failing health early after the second surgery. The rest of the animals recovered from the surgeries and 
progressively developed uremia (blood urea nitrogen levels $>30 \mathrm{mg} / \mathrm{dL}$ ) and anemia (absolute hematocrit values $5-10 \%$ below naïve control), which was regularly assessed by collecting and analyzing whole blood and serum samples.

\section{Naked pDNA delivery into rhesus skeletal muscle}

The procedure for hydrodynamic limb vein injections in rhesus monkeys has been described (Hagstrom et al., 2004). Briefly, the animal was kept under 1-2\% isoflurane anesthesia. A 20gauge intravenous catheter was inserted into a distal vein of a limb. A pediatric-sized tourniquet cuff (Delfi Medical Innovations, Vancouver, Canada) was placed just above the elbow or knee and was inflated $(780 \mathrm{mmHg})$ to transiently block blood flow. The injection volume was determined by measuring the volume of the limb (only the estimated target area distal from the tourniquet) by fluid displacement and multiplying it with 0.4 . The proper amount of pDNA was diluted in the calculated volume of sterile NSS and loaded into a syringe that was attached to the catheter. The solution was delivered by a Harvard syringe pump at a rate of $2 \mathrm{ml} / \mathrm{second}$. After two minutes, the tourniquet cuff was deflated and removed. The animal was then observed until it recovered from anesthesia and began using the injected limb. All but one of the rhesus monkeys were young (2.5-3 years old) males with body weights between $2.9-4.8 \mathrm{~kg}$. One animal was an $8.2 \mathrm{~kg}, 13$ years old male.

\section{Assessing EPO expression levels and the physiological effects of EPO}

Before and after gene delivery, blood samples were collected at various time points. From rats, the blood was collected from the jugular vein under general isoflurane anesthesia. For rhesus monkeys we used $15 \mathrm{mg} / \mathrm{kg}$ Ketamine $\mathrm{HCl}$ medication prior to drawing blood from a peripheral limb vein. Whole blood (with EDTA as an anticoagulant) was analyzed in a clinical laboratory to follow the changes in hemoglobin $(\mathrm{Hb})$, hematocrit (Hct), red and white blood cell counts, reticulocyte count and other parameters. Changes in absolute hematocrit values ( $\Delta \mathrm{Hct}$ ) were calculated by subtracting each animal's own pre-injection baseline Hct from the measured Hct value at each time point.

Serum samples from rhesus monkeys were also collected before and after the procedure to assess their creatine phosphokinase (CPK) and myoglobin concentrations. The samples were analyzed in a clinical laboratory using standard procedures.

Rhesus serum samples were analyzed for EPO concentration using a human EPO-specific ELISA kit that cross-reacts with the rhesus ortholog (R\&D Systems, Minneapolis, MN, USA). The antibody in the kit has lower avidity for rhesus EPO than for the human EPO used as a standard, leading to an approximately 4-fold under-estimation of actual EPO concentrations (Rivera et al., 2005). We report the original ELISA readings without correcting them for this 4-fold discrepancy.

\section{Performing therapeutic phlebotomy on rhesus monkeys}

When an EPO-treated rhesus monkey's Hct value exceeded 65\%, a therapeutic phlebotomy was performed to bring the Hct below $60 \%$. The amount of blood to be withdrawn was determined based on the following formula (used for pediatric patient management): volume to be exchanged $=$ body weight $(\mathrm{kg}) * 75 \mathrm{ml} / \mathrm{kg} *[($ actual Hct -60$) /$ actual Hct $)]$. The removed blood was replaced by an equal volume of sterile lactated Ringer's solution to supply fluid and electrolytes. The phlebotomy was performed under general isoflurane anesthesia.

\section{Statistical analysis}

For each study group the average, standard deviation and the standard error of the mean (SEM) were calculated and shown on the graphs. Comparisons of groups were performed using 
Analysis of Variance (ANOVA) and groups with p-values $<0.05$ were considered significantly different. In order to analyze the difference between groups across all time points, the groups were first compared using non-parametric Wilcoxon Rank Sum test. Then, a linear mixed effects model was applied with an autoregressive correlation structure to account for repeated measurements. The variability of different groups at specific time points was compared by performing Levene tests. The comparison of variability between groups across all time points was based on the Levene test results and on the analysis of the area under the curve (AUC).

\section{Results}

\section{Optimizing conditions for stepwise small pDNA dose delivery into adult rats}

Anemic patients typically need only a small, $<10 \%$ absolute increase in their hematocrit to reach the desired target value. To model this, we wanted to establish injection conditions in adult rats that would lead to an approximately $5 \%$ Hct increase. Within this paper, all mention of Hct changes, $\Delta \mathrm{Hct}$, refer to absolute increases or decreases of the hematocrit by the indicated value. Since reducing the HLV injection volume would make the procedure more attractive for the patient, we first wanted to identify the smallest injection volume that resulted in significant and reproducible EPO expression. A second optimization step involved the delivery of various pDNA doses in that small injection volume. The rate of injection was kept constant at $10 \mathrm{ml}$ per minute for all rat procedures. A group of 10 adult Lewis rats was used for each condition. Serum EPO levels could not be determined due to the lack of a reliable assay system for rat serum samples.

Figure 1 shows hematocrit changes at several time points after the delivery of a constant, high dose of $500 \mu \mathrm{g}$ mMCK-ratEPO pDNA in $10,7.5,5$ or $2.5 \mathrm{ml}$ normal saline solution (NSS). The control group received $500 \mu \mathrm{g}$ Empty-mMCK pDNA in $10 \mathrm{ml} \mathrm{NSS}$. Already 2 weeks postinjection, all four EPO-injected groups reached significantly higher Hct values than the control group $(\mathrm{p}<0.05)$ and this difference further increased $\left(\right.$ to $\left.\mathrm{p}<10^{-5}\right)$ at later time points. Four weeks after delivery, significant differences could also be detected between some EPO-injected groups. The groups injected with 10 or $2.5 \mathrm{ml}$ NSS had significantly lower Hct values than the 5 or $7.5 \mathrm{ml}$-injected groups ( $\mathrm{p}<0.05$ ). Differences between 5 versus $7.5 \mathrm{ml}$ and 10 versus 2.5 $\mathrm{ml}$ were not significant. Similar differences were observed in red blood cell counts and in hemoglobin values (data not shown). Part of the study was terminated at 12 weeks postinjection and only animals in the $5 \mathrm{ml}$ and $2.5 \mathrm{ml}$ groups were monitored longer to assess the longevity of the effect. With some fluctuation, Hct values remained stable between weeks 10 and 24 (Fig. 1). Based on the Wilcoxon Rank Sum test, these two groups were significantly different at all but one individual time point until the end of the study (at least $\mathrm{p}<0.05$ ). The $\mathrm{p}$ value for the comparison across all time points was 0.024 , indicating their overall significant difference.

From Figure 1 it is clear that when using this high, $500 \mu \mathrm{g} / \mathrm{animal}$, pDNA dose, even injections in $2.5 \mathrm{ml}$ resulted in over $20 \%$ Hct increase. Thus, we next injected rats with a series of decreasing pDNA doses $(250,100,25$ or $5 \mu \mathrm{g}$ mMCK-ratEPO) in $2.5 \mathrm{ml} \mathrm{NSS}$. The control group was injected with $250 \mu \mathrm{g}$ Empty-mMCK vector in $2.5 \mathrm{ml} \mathrm{NSS}$. Figure 2 illustrates $\Delta$ Hct values for these 5 groups and as a comparison it also shows the $\Delta$ Hct values of the $2.5 \mathrm{ml}$ group from the previous study, in which animals were injected with $500 \mu \mathrm{g} /$ animal dose. During the first 6 weeks after delivery, all four EPO-injected groups showed signs of increased hemopoiesis and the degree of change in their hematocrit values was proportional to the injected dose (Fig. 2). Between 14 and 42 days post-injection, all EPO-injected groups were significantly different from the control group $(\mathrm{p}<0.05)$. However, by 10 or 12 weeks after the injections the effect in the two groups receiving only 5 or $25 \mu \mathrm{g}$ pDNA, respectively, diminished and Hct values returned to baseline. The groups injected with 100 or $250 \mu \mathrm{g} / \mathrm{animal}$ pDNA dose maintained elevated hematocrits $>10 \%$ above baseline and remained significantly 
different both from the group injected with $500 \mu \mathrm{g} /$ animal pDNA and from groups either injected with lower doses or with the control pDNA ( $<<0.05)$. Conversely, the groups injected with 100 or $250 \mu \mathrm{g} /$ animal dose were not significantly different from each other at any time point. The two groups receiving 250 or $500 \mu \mathrm{g} /$ animal pDNA continued to maintain significantly elevated $(\mathrm{p}<0.05)$ Hct values beyond the 12 th week of the study, even though during that period both the control group and the group injected only with $25 \mu \mathrm{g} / \mathrm{animal} \mathrm{pDNA}$ showed 5-6\% increase in the hematocrit, which appears to be a natural part of the aging process (Fig. 2).

Since at its peak value (on day 42) the $25 \mu \mathrm{g} / \mathrm{animal} \mathrm{pDNA}$ dose resulted in $7.8 \%$ Hct increase and it could maintain $>5 \%$ elevated Hct for up to 10 weeks, we selected this dose and a $2.5 \mathrm{ml}$ injection volume as the optimal conditions for testing repeated small-dose pDNA injections in adult anemic rats.

\section{Treatment of anemia in a rat model by repeated small-dose injections}

The next objective of our studies was to test whether we can correct anemia in an animal model by triggering controlled levels of erythropoiesis after the repeated delivery of small doses of mMCK-ratEPO pDNA. To this end, we followed the fate of 6 groups of adult male Lewis rats for over 200 days. First, we collected blood from all the animals to establish baseline values for their hematological parameters and kidney function. The time of this first bleeding was considered as day 0 of the study. Then, we performed the two steps of kidney or sham surgery as described in the materials and methods section to induce anemia. Six weeks later (on day 63), all animals were bled and tested again and were assigned to the following groups. Two control groups comprised either naïve (Group $1 ; n=7$ ) or sham-operated animals (Group 2; $\mathrm{n}=10$ ) and did not receive HLV gene therapy. By this time, the 45 rats that recovered after the $5 / 6$ nephrectomy procedures showed signs of renal insufficiency and anemia. They had significantly increased blood urea nitrogen (BUN) levels at an average of $62.3+/-1.8 \mathrm{mg} / \mathrm{dL}$ versus $20.2+/-0.5 \mathrm{mg} / \mathrm{dL}$ in the controls $\left(\mathrm{p}<10^{-6}\right)$ (Fig. 3A) and creatinine levels at $0.84+/$ $-0.3 \mathrm{mg} / \mathrm{dL}$ versus $0.29+/-0.01 \mathrm{mg} / \mathrm{dL}$ in the controls $\left(\mathrm{p}<10^{-5}\right)$. As a result of inadequate EPO production by the remaining kidney tissue mass, the average hematocrit was only 39.5 $+/-0.35 \%$, while Hct in the naïve and sham-operated controls increased during these 63 days from an average of $42.0+/-1.2$ and $39.7+/-0.6$ to an average of $48.7+/-0.4 \%$ and $46.3+/$ $-0.3 \%$, respectively (Fig. 3B). This increase could be the result of aging, similarly to the changes observed earlier during the DNA dose study (Fig. 2). The 7-9\% divergence between the nephrectomized and control animals was highly significant $\left(\mathrm{p}<10^{-6}\right)$. At this time point (day 63 ), even the $2.4 \%$ difference between naive and sham-operated animals was statistically significant $(\mathrm{p}<0.001)$. However, this difference later diminished and was not significant at any other time point, suggesting that sham surgery resulted only in a mild and temporary decrease in hemopoiesis.

These results indicated that we had successfully created an animal model of kidney failurerelated anemia. The anemic animals were then assigned to four treatment groups. Group 3 $(\mathrm{n}=11)$ was injected once with $50 \mu \mathrm{g} / \mathrm{animal}$ Empty-mMCK control vector and was later reinjected twice with $25 \mu \mathrm{g} / \mathrm{animal}$ of the same control pDNA. Group $4(\mathrm{n}=11)$ received three doses of $25 \mu \mathrm{g} / \mathrm{animal} \mathrm{mMCK}$-ratEPO, for a total of $75 \mu \mathrm{g} / \mathrm{animal}$ EPO expression vector. Group $5(\mathrm{n}=11)$ was initially injected with $50 \mu \mathrm{g} / \mathrm{animal} \mathrm{mMCK}$-ratEPO vector and received two more $25 \mu \mathrm{g} /$ animal doses for a total of $100 \mu \mathrm{g} /$ animal delivered pDNA. Animals in Group $6(\mathrm{n}=12)$ received a single injection of $100 \mu \mathrm{g} / \mathrm{animal} \mathrm{mMCK}$-ratEPO. All injections were given in $2.5 \mathrm{ml} \mathrm{NSS}$. Serum and blood samples were collected from all the animals at various time points after pDNA delivery.

Figure $3 \mathrm{~A}$ illustrates the progressively worsening uremia during the course of the study in all groups of 5/6 nephrectomized animals compared to stable BUN values in the two control 
groups. Differences between the anemic and control groups were significant at all time points starting with day $63\left(\mathrm{p}<10^{-4}\right)$. Animals for Group 6, which was to be injected with the highest pDNA dose, were intentionally selected to have the lowest starting Hct values (a model of severe anemia). This was also reflected by the group's highest average BUN value on day 63 , which was significantly different $(\mathrm{p}<0.05)$ from those of the other three anemic groups. Due to the progression of kidney failure in all animals, these differences diminished over time.

Figure 3B demonstrates how the average hematocrit values of the groups changed during the study. As described above, after the surgeries and prior to gene delivery (on day 63), the average Hct values of all anemic groups were significantly lower $\left(\mathrm{p}<10^{-6}\right)$ than those of the controls (Fig. 3B). For Group 3, which was injected with the Empty-mMCK control pDNA, this remained true for the whole length of the study ( $\mathrm{p}$ values between 0.005 and $10^{-6}$ ). In contrast, Hct values of all three EPO-treated groups either reached or slightly surpassed (3-5\%) the average Hct of the naïve and sham-operated groups by the end of the study on day 203 (Fig. 3B). Hemoglobin values and red blood cell counts followed essentially identical trends (data not shown). These results indicated that in a global sense, HLV-mediated EPO gene therapy was successful in correcting the symptoms of kidney failure-related anemia by using either of the 3 dosing regimens, without treating the underlying pathological cause.

To better demonstrate the stepwise, additive effect of repeated EPO gene delivery, we also analyzed the data in a different way. We used the day 63 Hct value as the pre-treatment baseline and calculated $\Delta$ Hct by subtracting this baseline value from each individual animals' hematocrit values recorded at later time points. Figure $3 \mathrm{C}$ graphically illustrates how average $\Delta$ Hct values changed in the study groups during the 18 weeks of the treatment period. Actual $\Delta$ Hct values for the 4 pDNA-injected groups are also shown in Table 1 . Between 4 and 8 weeks after the first injection (days 105 and 133) the three EPO-injected groups not only showed signs of increased erythropoiesis, compared to the Empty-mMCK-injected control group $(\mathrm{p}<0.01)$, but the changes were also dose-dependent. Statistical analysis showed that at these time points animals injected with $100 \mu \mathrm{g}$ /animal pDNA (Gr.6) showed significantly higher erythropoiesis than animals injected either with 50 or $25 \mu \mathrm{g} / \mathrm{animal}$ dose (Gr.5 and Gr. 4 at $\mathrm{p}<0.05$ and $\mathrm{p}<0.0001$, respectively; Table 1$)$. The difference between Groups 4 and 5 was apparently dose-dependent, but did not quite reach statistical significance $(\mathrm{p}=0.107$; Table 1$)$. On day 168, four weeks after re-injecting Groups 4 and 5 with the second dose of $25 \mu \mathrm{g} / \mathrm{animal}$ mMCK-ratEPO, the average $\Delta$ Hct value in Group 5 almost reached that of Group 6 (14.2 versus 15.3 , $\mathrm{p}=0.727$; Fig. $3 \mathrm{C}$ and Table 1 ), while the average $\Delta$ Hct value in Group 4 was still lower (9.9). However, at this time point the difference between Groups 4 and 6 was no longer significant $(\mathrm{p}=0.058)$. As on day 133, the difference between Groups 4 and 5 appeared dosedependent, but was not statistically significant $(\mathrm{p}=0.108$; Table 1$)$. The third injection of 25 $\mu \mathrm{g} /$ animal EPO-expressing pDNA further increased hematocrit values in Group 4 to almost the same level as the peak value had been for Group 6: $16.5 \%$ cumulative increase in Group 4 versus $17.8 \%$ in Group 6. During the same time, Group 3 (treated only with the EmptymMCK control vector) showed escalating decline in Hct values (Fig. 3C and Table 1). Given the severe uremia and increasing degree of mortality in all nephrectomized groups, the study had to be terminated after day 203 and all animals were sacrificed. This prohibited long-term follow-up of the effect.

Based on the $\Delta$ Hct values shown in Table 1 , the change caused by the second and third injections of $25 \mu \mathrm{g} / \mathrm{animal} \mathrm{mMCK}$-ratEPO appeared smaller than the effect of the first injection of the same dose in Group 4. However, since the HLV procedure in rats involved minor surgery and some blood loss, both repeat procedures caused a drop in Hct as reflected by Hct changes in the control Group 3 (Fig. 3C and Table 1). The effect of the newly delivered gene dose had to make up for that loss. Also, the fact that the health of the animals became increasingly compromised by kidney failure during the last few weeks of the study could have an effect on 
their response. Since absolute hematocrit values in the treatment groups reached only a 56$58 \%$ maximum (Groups $4-5$ on day 203; Fig. 3B), just 3-5\% higher than the naïve group, the response was unlikely to be limited by the saturation of erythropoiesis. In the earlier rat studies optimizing the injection volume and pDNA dose, most animals surpassed 70-80\% absolute Hct values.

The results summarized in Table 1 provide evidence that the repeated delivery of small doses of mMCK-ratEPO had an additive effect. In Groups 4 and 5, the total correction of anemia was achieved by incrementally increasing the degree of erythropoiesis to normal levels.

\section{Dose-dependent EPO expression in rhesus skeletal muscle}

In order to test the dose-response correlation in non-human primates, we injected rhesus monkeys with either $3 \mathrm{mg}$ pDNA per $\mathrm{kg}$ body weight $(\mathrm{mg} / \mathrm{kg}$ ) or $6 \mathrm{mg} / \mathrm{kg}$ doses. Serum samples were collected to quantitate EPO expression and the physiological response was evaluated based on hematological parameters. Figure 4 illustrates average serum EPO concentrations and absolute changes in the animals' hematocrit values $(\Delta \mathrm{Hct})$ at various time points after single HLV injections. The peak serum EPO values for the CMV construct were $16.4+/-5.0 \mathrm{mIU} /$ $\mathrm{ml}$ or $31.2+/-2.7 \mathrm{mIU} / \mathrm{ml}$ after the delivery of 3 or $6 \mathrm{mg} / \mathrm{kg}$ pDNA dose, respectively (Fig. $4 \mathrm{~A})$. For mMCK-RhEPO the peak values were $6.4+/-2.1$ and $12.8+/-1.8 \mathrm{mIU} / \mathrm{ml}$ for the 3 and $6 \mathrm{mg} / \mathrm{kg}$ dose, respectively. Both constructs resulted in an average physiological response that was proportional to these serum concentrations: approximately $7-8 \% \Delta \mathrm{Hct}$ for the $3 \mathrm{mg} /$ $\mathrm{kg}$ dose and about $14-15 \%$ increase for the $6 \mathrm{mg} / \mathrm{kg}$ dose (Fig. 4B). Although these average values reflect an almost perfect dose-dependent response, there was some variability between individuals that we present and discuss later.

\section{The kinetics of EPO expression in rhesus monkeys is promoter-dependent}

One of the major requirements for successful gene therapy of chronic anemia is sustained, long-lasting EPO expression. Therefore, we assessed the effect of three promoters on the longevity of EPO expression and its physiological outcome in rhesus monkeys. The animals were injected with $6 \mathrm{mg} / \mathrm{kg}$ pDNA using constructs containing either the ubiquitous CMV or the muscle specific mMCK or hMCK promoters. Expression was assessed as described above. Figures $5 \mathrm{~A}$ and $5 \mathrm{~B}$ summarize results at time points for which data from at least 3 injections have become available.

The delivery of CMV-RhEPO resulted in a sharp increase in serum EPO levels that peaked on day 7 post-injection followed by gradual decline. By the end of 4 months, serum EPO concentrations essentially returned to the pre-injection baseline (Fig. 5A). The Hct rapidly increased in these animals for $\sim 2$ months, then returned to pre-treatment levels by the end of $\sim 6$ months (Fig. 5B). In contrast, delivery of the mMCK-RhEPO construct led to a lower and delayed peak of EPO expression on day 14, followed by low, but above-baseline, stable expression, which sustained high Hct levels long-term (Figs. 5A-B). In spite of the markedly lower initial serum EPO concentrations (only $12.8 \mathrm{mIU} / \mathrm{ml}$ average on day 14 versus $31.2 \mathrm{mIU} /$ $\mathrm{ml}$ on day 7 for the CMV construct), the mMCK-RhEPO construct resulted in comparable Hct peak values (58.3\% average Hct on day 84 compared with $57.9 \%$ Hct on day 56 for CMVRhEPO, Figs. 5A-B). Expression from the hMCK promoter essentially lacked the initial serum EPO peak observed for the other two promoters and average serum EPO concentrations remained very low at all time points (Fig. 5A). Interestingly, even this minimal EPO expression increased the rate of hemopoiesis and slowly lead to a final $\sim 10 \%$ absolute change in the hematocrit at its peak, 4 months after the injections (average $50.3 \%$ peak Hct on day 112, Fig. $5 B)$. 
Figure 5C shows the serum EPO and Hct values of two individual animals that have been followed for over a year. One monkey (\#139-02) was injected twice (on day 0 and day 140) with $6 \mathrm{mg} / \mathrm{kg}$ CMV-RhEPO and finally, on day 294, with $6 \mathrm{mg} / \mathrm{kg} \mathrm{mMCK}-\mathrm{RhEPO}$. While the first two injections resulted only in temporary expression and Hct changes, this last delivery appears to follow the kinetics of other mMCK-RhEPO injections as described above. The delivery of the mMCK construct lead to such intense hemopoiesis that 20 weeks after the injection the animal's hematocrit exceeded $65 \%$. One therapeutic phlebotomy has been performed to decrease the Hct to 60\% (Fig. 5C). The other animal (\#139-03) received a single dose of $6 \mathrm{mg} / \mathrm{kg} \mathrm{mMCK}-\mathrm{RhEPO}$ on day 0 and has stably maintained elevated Hct values $\sim 10 \%$ above baseline for 450 days (Fig. 5C). Both animals are still being observed.

These results indicate that after delivering the mMCK-RhEPO construct, stable EPO expression can be achieved in the skeletal muscles of non-human primates and this results in a long-term physiological response. Furthermore, data obtained with the hMCK promoter suggest that over time, even very low serum EPO levels can build up and maintain a steady rate of erythropoiesis.

\section{The reproducibility and variability of hydrodynamic limb vein delivery}

Each group of 10 animals in the above-described rat studies for optimizing injection volumes and pDNA doses were actually injected by two equally experienced animal technicians with each worker injecting 5 animals out of the group of 10 . They performed the injections at the same time and followed a standard operating procedure. Table 2 shows the results of the injection volume optimization study after analyzing data in the two separate sub-groups 42 days post-injection. The sub-groups yielded very similar results. When comparing them at all time points using ANOVA analysis, the resulting p-values ranged between 0.31 and 0.93 , meaning that none of the sub-groups was significantly different from its matching pair at any time point during the study. The analysis of sub-groups in the pDNA dose study also yielded similar results, although there was one sub-group that was significantly different $(\mathrm{p}<0.05)$ from its matching pair at three out of 9 time points. Overall, the results indicated that the outcome of the standardized HLV delivery procedure was not sensitive to the individual performance of different technicians.

The degree of variability after performing HLV injections under various conditions was also assessed by comparing standard deviation and SEM values obtained in the rat studies. We noticed that performing the HLV procedure using higher injection volumes or larger pDNA doses resulted in smaller SEM values than injecting a very small amount of pDNA in a minimal volume. Statistical analysis of the data (using Levene tests) confirmed that performing the delivery of $500 \mu \mathrm{g}$ pMCK-ratEPO pDNA in $2.5 \mathrm{ml}$ volume resulted in significantly higher variability than the same injections in $5 \mathrm{ml}$ fluid at most time points of the study. The comparison of variability between these groups across all time points also suggested that they were significantly different $(\mathrm{p}=0.0018)$. Graphs on Fig. $6 \mathrm{~A}-\mathrm{B}$ visually illustrate this by plotting the hematocrit changes in individual animals. The sub-optimal $2.5 \mathrm{ml}$ volume resulted in a markedly wider distribution than that of animals in the 5 ml-injected group (Fig. 6A-B).

In order to assess variability in non-human primates, the results of six identical, individual injections using $6 \mathrm{mg} / \mathrm{kg}$ CMV-RhEPO were plotted in Figure 7. There is a fairly wide distribution both in serum EPO levels (Fig. 7A) and in Hct changes (Fig. 7B). The range of serum EPO concentrations on day 2 post-injection was between $15-53 \mathrm{mIU} / \mathrm{ml}$, and on day 7 between $21-41 \mathrm{mIU} / \mathrm{ml}$. This is a 3.5 -fold difference between the lowest and highest values on day 2 post-injection. Three- to four-fold differences could also be observed at later time points (Fig. 7A). The effect of this variable rate of EPO production is also reflected by the physiological response. Figure 7B shows $\Delta$ Hct values for the same animals. The peak values are scattered between 28 and 84 days after delivery and between a low $6.2 \%$ and a high $22.6 \%$, 
a 3.6-fold difference (Fig. 7B). Interestingly, higher Hct values did not strictly correlate with higher serum EPO concentrations. For example, injection \#2 resulted in the second highest serum EPO concentration $(35.4 \mathrm{mIU} / \mathrm{ml}$ on day 7$)$, yet it led only to a $10 \%$ increase in the hematocrit. In contrast, injection \#3 yielded a lower peak serum level $(29.8 \mathrm{mIU} / \mathrm{ml}$ on day 7$)$, yet this triggered a more intense hemopoiesis leading to a $21.2 \%$ peak $\Delta$ Hct 56 days after pDNA delivery. Animal \#6 (which was the single older animal in the study group) consistently showed the lowest expression and the lowest physiological response, while animal \#5 had extremely high serum EPO levels leading to the highest change in the hematocrit (Fig. 7A-B). Similar 2-3-fold variability could be observed in animals injected with mMCK-RhEPO and hMCK-RhEPO plasmid constructs (data not shown).

\section{The safety of the procedure}

To assess the degree of muscle damage caused by the HLV procedure we collected serum samples from the untreated animals and then 5 minutes and 48 hours after each injection and determined their creatine phosphokinase (CPK) and myoglobin concentration. The range of CPK before the procedure was between 201-926 U/L. Five minutes after the injection this increased to 302-1499 U/L. The highest value (2112 U/L) was measured in one of the samples collected 2 days after gene delivery, although CPK values typically declined by that time to a range of 154-677 U/L. The animal with the $2112 \mathrm{U} / \mathrm{L} \mathrm{CPK}$ level was re-tested on day 7 and by that time it had only $239 \mathrm{U} / \mathrm{L}$ CPK. Serum myoglobin concentrations for these same time points were in the range of 22.1-255.6, 49.6-452.8 and 0.7-87.8 $\mathrm{ng} / \mathrm{ml}$, respectively. These $\mathrm{CPK}$ and myoglobin concentrations are all in the range that can be observed after heavy exercise without any negative effect on the individual's health. Even the three repeated injections of animal \#139-02 (Fig. 5) did not lead to unusually high CPK and myoglobin levels or any other sign of increased toxicity, suggesting that repetitive delivery of small pDNA doses is a feasible approach. The detailed analysis of the safety studies will be reported elsewhere.

Another important indicator of the safety of HLV-mediated gene delivery was the observation of the monkeys' behavior after the injection. As part of the animal care protocol, they were given a single dose of buprenorphine ( 0.01 to $0.03 \mathrm{mg} / \mathrm{kg}$, IM) peri-procedurally as an analgesic. They became active between 10-30 minutes after the procedure, depending on how rapidly the effect of anesthesia wore off. Once they fully recovered, they willingly used their injected limbs to move around their cages and pick up food. They did not favor one side or show any signs of lameness. Aside from some petechiae under the skin of the treated limb, no adverse reactions or untoward effects could be observed.

\section{Discussion}

While the normal reference range for human hemoglobin values is between $12-16 \mathrm{~g} / \mathrm{dL}$ for women and 13-18 g/dL for men, the current guidelines of the National Kidney Foundation's (NKF) Kidney Disease Outcomes Quality Initiative for the management of anemia recommends a considerably lower target range for anemic patients: greater than $11.0 \mathrm{~g} / \mathrm{dL}$, but not to exceed $13.0 \mathrm{~g} / \mathrm{dL}$ (Anonymous, 2006; Remuzzi and Ingelfinger, 2006). These hemoglobin values translate to approximately $33-39 \%$ hematocrit - a very narrow window. It is also recommended to reach this target hematocrit within 4 months of starting recombinant EPO therapy. Patients with severe anemia $(<7.0 \mathrm{~g} / \mathrm{dL} \mathrm{Hb}$ or $21 \% \mathrm{Hct})$ need $>10 \%$ absolute increase in their Hct to reach this range, but the majority of patients start getting treatment when their hemoglobin drops below $9 \mathrm{~g} / \mathrm{dL}(\sim 27 \% \mathrm{Hct})$. Thus, they need only about $10 \% \mathrm{Hct}$ increase. The findings of some clinical trials have suggested that the complete correction of anemia up to the normal range does not provide additional benefits and may actually jeopardize the patient's health (Drueke et al., 2006; Remuzzi and Ingelfinger, 2006; Singh et al., 2006). If gene therapy is to replace EPO protein therapy, it should also be able to maintain Hct values 
in this recommended narrow range. Due to this, the regulation of EPO expression has always been considered to be the cornerstone of a clinically viable gene therapy treatment for chronic anemia. The major goal of this study was to explore the clinical potential of controlling EPO expression at the level of the administered gene dose.

When we initially developed the HLV technology, one goal was to optimize conditions to reach maximal gene expression. Both the volume of the injection fluid and the pDNA dose were selected to obtain peak performance, while keeping toxicity at a minimum. For young (120150 gram) Sprague-Dawley rats maximum luciferase expression was obtained by injecting $1000 \mu \mathrm{g} / \mathrm{animal}$ pDNA in $3 \mathrm{ml}$ volume at a $10 \mathrm{ml} /$ minute delivery rate (Hagstrom et al., 2004). However, for the treatment of anemia the goal was to find conditions that lead to the minimal level of transgene expression that can still trigger hemopoiesis. Also, we used significantly larger, adult animals ( 300 gram) that had larger tissue mass on the hind limbs. Thus, based on the previously established range (Hagstrom et al., 2004), we had to find the set of injection parameters that were most suitable for these studies. We found that although the optimal injection volume for these adult rats was between 5 and $7.5 \mathrm{ml}$, gene delivery in 2.5 $\mathrm{ml}$ still resulted in sufficient expression levels. When we measured the volume of the hind limb of adult rats with 250-300 g weight, we found that the average volume was $9.8 \mathrm{ml}$. Thus, the injected $2.5 \mathrm{ml}$ was only $\sim 25 \%$ of the target tissue volume. In contrast, for large animals such as rhesus and dog, we have been delivering the pDNA in $40 \%$ of the target tissue volume to get maximal expression. As mentioned in the Introduction, this large volume of injected fluid has raised some concerns about the clinical viability of the HLV procedure, and although all the animal studies performed so far suggest that those concerns are unsubstantiated, lowering the injection volume from $40 \%$ to $25 \%$ of the target tissue volume will still make the procedure more attractive. Our results demonstrate that sub-optimal conditions are acceptable if the goal of gene delivery is not to maximize expression levels.

We found that injecting $25 \mu \mathrm{g}$ /animal mMCK-ratEPO pDNA in $2.5 \mathrm{ml}$ volume resulted in $\sim 5 \%$ $\Delta$ Hct in adult Lewis rats. Next, we demonstrated that three repeated injections of this small dose resulted in an approximately $15 \%$ cumulative Hct change in a rat anemia model. The effect of delivering a single $50 \mu \mathrm{g} / \mathrm{animal}$ dose followed by two additional $25 \mu \mathrm{g} / \mathrm{animal}$ doses was also additive. In both cases the effect was similar to that of a single injection at $100 \mu \mathrm{g} /$ animal dose, which lead to almost $18 \%$ Hct increase. Similar studies to demonstrate the additive effect of repeated HLV delivery of small pDNA doses into rhesus monkeys are now in progress.

A pDNA dose of $25 \mu \mathrm{g}$ for a 250 gram rat translates into a dose of $100 \mu \mathrm{g}$ per kg body weight. When we initiated our primate studies, we found that in rhesus monkeys even a 10-fold higher pDNA dose, $1 \mathrm{mg} / \mathrm{kg}$, was insufficient to trigger erythropoiesis. When we systematically compared serum EPO levels and the resulting increase in hematocrit values in mice, rats, dogs and monkeys after the delivery of CMV-RhEPO, we found that at least 20-30-fold higher pDNA doses were needed in the dog and monkey than in rodents to reach the same effect (data not shown). This was surprising, because using luciferase, $\beta$-galactosidase and dystrophin we had earlier demonstrated that the efficiency of HLV pDNA delivery was comparable in small rodents and larger animals (Hagstrom et al., 2004). It was unlikely then, that the delivery step of EPO expression vectors to monkey skeletal muscle was causing the lower efficiency of EPO production. The phenomenon of lower EPO expression efficiency in non-human primates as compared with those obtained in small rodents was also reported after electroporation-mediated delivery of EPO-expressing naked pDNA (Fattori et al., 2005). These authors improved their EPO expression levels in cynomolgus monkeys by using a construct containing a codonoptimized version of the cynomolgus EPO cDNA and also by replacing the EPO secretory signal peptide by that of human tissue plasminogen activator (hTPA) (Kim et al., 1997; Fattori et al., 2005). Improving expression efficiency of EPO in skeletal muscle of primates (and 
humans) would make gene therapy more economical and we are currently working on developing new constructs to address this.

The transcriptional activity of a promoter is affected by many factors including the tissue environment and cis-acting elements of the plasmid construct such as introns, 3' UTRs, CpG content and occasionally even the expressed gene itself. Considering the potential effect of all these variables, we compared expression constructs that differed only in the promoter region, in an otherwise identical vector backbone. Under these conditions, and delivering equal $\mathrm{mg} /$ $\mathrm{kg}$ doses instead of equimolar amounts, the three tested promoter constructs resulted in markedly different expression levels and expression kinetics. While expression from the CMV promoter initially exceeded that from the mMCK construct, their ratio changed over time and 6-8 weeks after delivery the average serum level was already higher in mMCK-injected animals, maintaining a longer-lasting, stable stimulus for continued erythropoiesis over 450 days. It was surprising that the CMV promoter was unable to maintain stable expression. We had earlier delivered CMV-MUSEAP pDNA into the hind limb of mice and observed stable expression for well over a year (unpublished data). Others have also reported long-term EPO expression in a rhesus monkey after the intramuscular injection of AAV-CMV-RhEPO particles (Rivera et al., 2005). On the other hand, the silencing of CMV promoter activity in various tissues, including skeletal muscle and liver, has also been shown both after naked DNA or viral delivery and also in transgenic animals (Loser et al., 1998; Herweijer et al., 2001; Brooks et al., 2004). CpG methylation and heterochromatinization triggered by bacterial sequence elements have both been blamed for the effect (Brooks et al., 2004; Chen et al., 2004). It is not clear why certain experimental conditions allow long-term expression while the same promoter becomes shut down in other studies. It is known that pDNA can persist in the post-mitotic nuclei of myofibers in an eposimal form for years (Wolff et al., 1992). The pDNA can be lost faster, if there is a high rate of muscle turn-over for example due to heavy exercise or due to medical conditions. However, in these studies the rate of muscle turnover would likely be the same in the CMV-RhEPO and mMCK-RhEPO-injected animals, and the latter could maintain stable expression. Immune rejection selectively targeting CMV-produced EPO could also be ruled out based on undetectable anti-EPO antibodies in the serum (data not shown) and also based on the successful re-injection of an animal three times using both the CMV- and the mMCK-RhEPO constructs (Fig. 5). The slow rate of decrease of EPO expression was also peculiar, not consistent with immune rejection. We suspect that the loss of EPO expression was due to promoter inactivation, but it would be challenging to obtain reliable quantitative data from non-human primates to support this assertion. Thus, since there is no mechanistic information why expression from the CMV-RhEPO plasmid diminished in the skeletal muscle of rhesus monkeys, it is hard to predict how this promoter will behave in humans.

Due to the long half-life of erythrocytes ( 120 days), once an initial high expression peak of EPO triggers excessive red blood cell production, it may take months until hematocrit values return to normal. Thus, the fact that the hMCK construct did not have an apparent initial peak, but rather maintained a very low $(<5 \mathrm{mIU} / \mathrm{ml})$ level of expression for several months, makes it a promising candidate for clinical use. Surprisingly, even these very low serum EPO levels could slowly build up hematocrit values to an average of $10 \%$ absolute Hct increase by 3-4 months after gene delivery. Our current data are too limited to judge how much longer elevated Hct values would be maintained. Also, since the promoter is of human origin, its delivery to human muscle may result in different expression levels and kinetics, which can be tested in vitro, in primary cell cultures, before initiating clinical studies.

When we delivered a lower pDNA dose of the CMV and mMCK constructs $(3 \mathrm{mg} / \mathrm{kg}$ instead of $6 \mathrm{mg} / \mathrm{kg}$ ) we got proportionally lower average EPO expression and Hct increases in monkeys. These results were very encouraging, because they matched the need of a typical 
anemic patient very well: 6-8\% absolute Hct increase within 1-2 months (Fig. 4). However, at this lower dose variability meant that the physiological response in some monkeys was minimal and did not last longer than 6-10 weeks, while others mounted a proportionally low but lasting response. A similar phenomenon could also be observed in rats: variability increased under sub-optimal conditions, including animals with minimal response, and at low pDNA doses the effect diminished faster than at higher doses ( 25 and $5 \mu \mathrm{g} /$ animal groups on Fig. 2). Since this was also observed using mMCK promoter constructs, which are able to express longterm, we speculated that in compensation for EPO expression in the muscle, these healthy animals could shut down their endogenous EPO expression completely. In animals that might have had a naturally high baseline EPO level before treatment, the expressed exogenous EPO simply replaced normal EPO expression instead of adding to it, and thus had no lasting effect. In other individuals that might have had low natural EPO baseline, the ectopic expression could remain above the normal levels and stimulate erythropoiesis long-term, even if all endogenous EPO production was down-regulated. When we measured EPO concentration in kidney homogenates isolated from naïve and EPO-injected rhesus monkeys, we found that the tissue from the naïve animal had 6-fold higher EPO content than that of the EPO-treated one (data not shown). This supports our hypothesis that the original, normal serum EPO baseline of the individual sets a threshold for EPO gene therapy that has to be surpassed by expression from the ectopic site in order to have a lasting physiological effect.

It has also been reported that expression of exogenous EPO down-regulated the synthesis of endogenous EPO in the kidneys in response to phlebotomy-induced hypoxia (Maruyama et al., 2001a). This might be explained by the already elevated Hct, which would reduce the extent of hypoxia after phlebotomy. However, the phenomenon also supports our contention that EPO expression in the kidneys and at the ectopic site(s) are likely to be interrelated, resulting in a threshold effect. In a clinical setting the height of this threshold would depend on the patients' residual ability to synthesize EPO and is expected to be different for patients suffering from end-stage renal failure, AIDS, cancer or other chronic diseases. This adds another factor to the expected variability of the patients' response and further underlines the need for individually tailored gene dosing options.

Variability in the patients' response to EPO is not restricted to gene therapy. Physicians currently prescribing recombinant human EPO therapy have to deal with similar challenges. Some factors that play a role are the patients' baseline hematocrit, baseline serum EPO level, clearance rate of circulating EPO, iron deficiency and various medical problems and their treatments that are not related to anemia and its underlying pathology. Due to these factors, both the initial and the maintenance dose that is needed to elevate the hematocrit to the target level and then stably maintain it can vary in a 10-fold range. For example, for EPOGEN ${ }^{\circledR}$ the mean maintenance dose is around 75 Units $/ \mathrm{kg}$, injected three times a week, but almost $10 \%$ of the patients does well on as low as 25 Units $/ \mathrm{kg}$ dose, while another $10 \%$ requires $>200$ Units/ $\mathrm{kg}$. To fit the treatment to the individual patient's need, the physician has to painstakingly titrate the dose. We find it promising that in our studies with healthy rhesus monkeys we did not see 10-fold differences between EPO expression levels and the ensuing physiological response.

A potential adverse effect of EPO replacement therapies has been the development of neutralizing antibodies against both the exogenous and endogenous EPO. This leads to autoimmune pure red cell aplasia. We initially suspected that animals injected with CMVRhEPO might be affected by an anti-EPO immune response, leading to declining levels of circulating EPO and consequently declining Hct values. However, we have been unable to detect anti-EPO antibodies in the serum. Also, the fact that we could repeatedly elicit a longlasting physiological response even after the effect of previous injections had worn off (Fig. $5 \mathrm{C})$, suggests that the decline of serum EPO concentrations and the gradual decrease of red 
blood cell production is not caused by neutralizing antibodies. We have treated 22 rhesus monkeys and over 200 rats by injecting rhesus or rat EPO expression plasmid constructs into the limb and none of them have developed lower than normal red blood cell counts. In contrast, when rhesus EPO expression vectors were delivered into cynomolgus monkeys using high doses of AAV vectors, a high percent of the treated animals developed anti-EPO antibodies and severe autoimmune anemia (Chenuaud et al., 2004a;Gao et al., 2004). Potential explanations for the high frequency of this adverse effect in those studies include the presence of viral antigens, the presence of other foreign proteins due to drug-regulatable expression constructs and, most importantly, the extremely high level of expression. Serum EPO concentrations reached $10^{3}-10^{5} \mathrm{mIU} / \mathrm{ml}$, compared to the highest value of $35 \mathrm{mIU} / \mathrm{ml}$ in our approach. It is also higher than the natural EPO response of $\sim 5,000 \mathrm{mIU} / \mathrm{ml}$ in mice and monkeys that could be elicited by extreme phlebotomy or 18 hours of experimental hypoxia (Koury et al., 1989;Fisher et al., 1996). At that extremely high level of expression it is possible that aggregates and misfolded protein products are also generated, triggering an immune response. This is highly unlikely in our proposed treatment protocol.

In conclusion, the main findings of this study are that (1) for EPO gene delivery, we can select an injection volume from the lower end of the effective range for the HLV procedure and this may make this treatment option even more attractive for patients; (2) the extent and longevity of the physiological response after EPO gene delivery are dose- and promoter-dependent providing means to control the outcome of the treatment; (3) repeated small-dose injections of EPO-encoding pDNA have an additive effect leading to gradually increasing EPO expression until the desired level of hemopoiesis is attained; (4) in spite of some variability at the level of delivery and at the individual's response to a certain serum EPO concentration, results are reasonably reproducible; (5) based on the pDNA dose needed to achieve a 5-10\% absolute increase in the hematocrit in non-human primates, we expect the procedure to be competitive with current treatment options and further studies aimed at improving expression efficiency will make it even more economical. These characteristics, combined with the minimally invasive nature of the HLV delivery procedure, support our contention that this approach can be developed into a simple, safe and flexible clinical gene therapy treatment for the long-term management of chronic anemia. Clinical studies will be needed to test expression efficiency, longevity and pDNA dosing options for humans.

\section{Acknowledgements}

This work was supported by a grant from the National Institutes of Health (R44 DK062011). We thank Dr. Jens C. Eickhoff (UW-Madison, Department of Biostatistics \& Medical Informatics, Madison, WI) for his expert assistance with the statistical analysis of our data, and Patricia Kleinpeter (Transgene, Strasbourg, France) for providing the human MCK promoter. The authors also thank Tracy Brunner and Tracie Milarch for excellent technical assistance.

\section{References}

ANAGNOSTOU A, VERCELLOTTI G, BARONE J, FRIED W. Factors which affect erythropoiesis in partially nephrectomized and sham-operated rats. Blood 1976;48:425-433. [PubMed: 953364]

ANONYMOUS. CPG and CPR 2.1. Hb Range. Am J Kidney Dis 2006;47:S33-S53.

AURICCHIO A, RIVERA VM, CLACKSON T, O'CONNOR EE, MAGUIRE AM, TOLENTINO MJ, BENNETT J, WILSON JM. Pharmacological regulation of protein expression from adeno-associated viral vectors in the eye. Mol Ther 2002;6:238-242. [PubMed: 12161190]

BINLEY K, ASKHAM Z, IQBALL S, SPEARMAN H, MARTIN L, DE ALWIS M, THRASHER AJ, ALI RR, MAXWELL PH, KINGSMAN S, NAYLOR S. Long-term reversal of chronic anemia using a hypoxia-regulated erythropoietin gene therapy. Blood 2002;100:2406-2413. [PubMed: 12239150]

BLE A, FINK JC, WOODMAN RC, KLAUSNER MA, WINDHAM BG, GURALNIK JM, FERRUCCI L. Renal function, erythropoietin, and anemia of older persons: the InCHIANTI study. Arch Intern Med 2005;165:2222-2227. [PubMed: 16246987] 
BOVEN K, KNIGHT J, BADER F, ROSSERT J, ECKARDT KU, CASADEVALL N. Epoetinassociated pure red cell aplasia in patients with chronic kidney disease: solving the mystery. Nephrol Dial Transplant 2005;20(Suppl 3):iii33-40. [PubMed: 15824129]

BROOKS AR, HARKINS RN, WANG P, QIAN HS, LIU P, RUBANYI GM. Transcriptional silencing is associated with extensive methylation of the CMV promoter following adenoviral gene delivery to muscle. J Gene Med 2004;6:395-404. [PubMed: 15079814]

CHEN ZY, HE CY, MEUSE L, KAY MA. Silencing of episomal transgene expression by plasmid bacterial DNA elements in vivo. Gene Ther 2004;11:856-864. [PubMed: 15029228]

CHENUAUD P, LARCHER T, RABINOWITZ JE, PROVOST N, CHEREL Y, CASADEVALL N, SAMULSKI RJ, MOULLIER P. Autoimmune anemia in macaques following erythropoietin gene therapy. Blood 2004a;103:3303-3304. [PubMed: 14739218]

CHENUAUD P, LARCHER T, RABINOWITZ JE, PROVOST N, JOUSSEMET B, BUJARD H, SAMULSKI RJ, FAVRE D, MOULLIER P. Optimal design of a single recombinant adenoassociated virus derived from serotypes 1 and 2 to achieve more tightly regulated transgene expression from nonhuman primate muscle. Mol Ther 2004b;9:410-418. [PubMed: 15006608]

DAVIS B, NGUYEN J, STOLTZ D, DEPPING D, EXCOFFON KJ, ZABNER J. Adenovirus-mediated erythropoietin production by airway epithelia is enhanced by apical localization of the coxsackieadenovirus receptor in vivo. Mol Ther 2004;10:500-506. [PubMed: 15336650]

DRUEKE TB, LOCATELLI F, CLYNE N, ECKARDT KU, MACDOUGALL IC, TSAKIRIS D, BURGER HU, SCHERHAG A. Normalization of Hemoglobin Level in Patients with Chronic Kidney Disease and Anemia. N Engl J Med 2006;355:2071-2084. [PubMed: 17108342]

FATTORI E, CAPPELLETTI M, ZAMPAGLIONE I, MENNUNI C, CALVARUSO F, ARCURI M, RIZZUTO G, COSTA P, PERRETTA G, CILIBERTO G, LA MONICA N. Gene electro-transfer of an improved erythropoietin plasmid in mice and non-human primates. J Gene Med 2005;7:228236. [PubMed: 15515133]

FAVRE D, BLOUIN V, PROVOST N, SPISEK R, PORROT F, BOHL D, MARME F, CHEREL Y, SALVETTI A, HURTREL B, HEARD JM, RIVIERE Y, MOULLIER P. Lack of an immune response against the tetracycline-dependent transactivator correlates with long-term doxycyclineregulated transgene expression in nonhuman primates after intramuscular injection of recombinant adeno-associated virus. J Virol 2002;76:11605-11611. [PubMed: 12388721]

FISHER JW. Erythropoietin: physiology and pharmacology update. Exp Biol Med (Maywood) 2003;228:1-14. [PubMed: 12524467]

FISHER JW, KOURY S, DUCEY T, MENDEL S. Erythropoietin production by interstitial cells of hypoxic monkey kidneys. Br J Haematol 1996;95:27-32. [PubMed: 8857934]

GAO G, LEBHERZ C, WEINER DJ, GRANT R, CALCEDO R, MCCULLOUGH B, BAGG A, ZHANG Y, WILSON JM. Erythropoietin gene therapy leads to autoimmune anemia in macaques. Blood 2004;103:3300-3302. [PubMed: 14695227]

GOVERDHANA S, PUNTEL M, XIONG W, ZIRGER JM, BARCIA C, CURTIN JF, SOFFER EB, MONDKAR S, KING GD, HU J, SCIASCIA SA, CANDOLFI M, GREENGOLD DS, LOWENSTEIN PR, CASTRO MG. Regulatable gene expression systems for gene therapy applications: progress and future challenges. Mol Ther 2005;12:189-211. [PubMed: 15946903]

HAGSTROM JE, HEGGE J, ZHANG G, NOBLE M, BUDKER V, LEWIS DL, HERWEIJER H, WOLFF JA. A Facile Non-Viral Method for Delivering Genes and siRNAs to Skeletal Muscle of Mammalian Limbs. Mol Ther 2004;10:386-398. [PubMed: 15294185]

HERWEIJER H, ZHANG G, SUBBOTIN VM, BUDKER V, WILLIAMS P, WOLFF JA. Time course of gene expression after plasmid DNA gene transfer to the liver. J Gene Med 2001;3:280-291. [PubMed: 11437333]

KIM CH, OH Y, LEE TH. Codon optimization for high-level expression of human erythropoietin (EPO) in mammalian cells. Gene 1997;199:293-301. [PubMed: 9358069]

KOURY ST, KOURY MJ, BONDURANT MC, CARO J, GRABER SE. Quantitation of erythropoietinproducing cells in kidneys of mice by in situ hybridization: correlation with hematocrit, renal erythropoietin mRNA, and serum erythropoietin concentration. Blood 1989;74:645-651. [PubMed: 2752138] 
LAMARTINA S, ROSCILLI G, RINAUDO CD, SPORENO E, SILVI L, HILLEN W, BUJARD H, CORTESE R, CILIBERTO G, TONIATTI C. Stringent control of gene expression in vivo by using novel doxycycline-dependent trans-activators. Hum Gene Ther 2002;13:199-210. [PubMed: 11812277]

LATTA-MAHIEU M, ROLLAND M, CAILLET C, WANG M, KENNEL P, MAHFOUZ I, LOQUET I, DEDIEU JF, MAHFOUDI A, TRANNOY E, THUILLIER V. Gene transfer of a chimeric transactivator is immunogenic and results in short-lived transgene expression. Hum Gene Ther 2002;13:1611-1620. [PubMed: 12228016]

LOSER P, JENNINGS GS, STRAUSS M, SANDIG V. Reactivation of the previously silenced cytomegalovirus major immediate-early promoter in the mouse liver: involvement of NFkappaB. J Virol 1998;72:180-190. [PubMed: 9420214]

MARUYAMA H, ATAKA K, GEJYO F, HIGUCHI N, ITO Y, HIRAHARA H, IMAZEKI I, HIRATA M, ICHIKAWA F, NEICHI T, KIKUCHI H, SUGAWA M, MIYAZAKI J. Long-term production of erythropoietin after electroporation-mediated transfer of plasmid DNA into the muscles of normal and uremic rats. Gene Ther 2001a;8:461-468. [PubMed: 11313825]

MARUYAMA H, ATAKA K, HIGUCHI N, SAKAMOTO F, GEJYO F, MIYAZAKI J. Skin-targeted gene transfer using in vivo electroporation. Gene Ther 2001b;8:1808-1812. [PubMed: 11803401]

NORDSTROM JL. The antiprogestin-dependent GeneSwitch system for regulated gene therapy. Steroids 2003;68:1085-1094. [PubMed: 14668002]

REMUZZI G, INGELFINGER JR. Correction of Anemia -- Payoffs and Problems. N Engl J Med 2006;355:2144-2146. [PubMed: 17108347]

RIVERA VM, GAO GP, GRANT RL, SCHNELL MA, ZOLTICK PW, ROZAMUS LW, CLACKSON T, WILSON JM. Long-term pharmacologically regulated expression of erythropoietin in primates following AAV-mediated gene transfer. Blood 2005;105:1424-1430. [PubMed: 15507527]

RIZZUTO G, CAPPELLETTI M, MENNUNI C, WIZNEROWICZ M, DEMARTIS A, MAIONE D, CILIBERTO G, LA MONICA N, FATTORI E. Gene electrotransfer results in a high-level transduction of rat skeletal muscle and corrects anemia of renal failure. Hum Gene Ther 2000;11:1891-1900. [PubMed: 10986561]

SINGH AK, SZCZECH L, TANG KL, BARNHART H, SAPP S, WOLFSON M, REDDAN D. Correction of Anemia with Epoetin Alfa in Chronic Kidney Disease. N Engl J Med 2006;355:20852098. [PubMed: 17108343]

TOUMI H, HEGGE J, SUBBOTIN V, NOBLE M, HERWEIJER H, BEST TM, HAGSTROM JE. Rapid intravascular injection into limb skeletal muscle: a damage assessment study. Mol Ther 2006;13:229_ 236. [PubMed: 16185934]

TRIPATHY SK, SVENSSON EC, BLACK HB, GOLDWASSER E, MARGALITH M, HOBART PM, LEIDEN JM. Long-term expression of erythropoietin in the systemic circulation of mice after intramuscular injection of a plasmid DNA vector. Proc Natl Acad Sci USA 1996;93:10876-10880. [PubMed: 8855275]

WANG J, VOUTETAKIS A, PAPA M, RIVERA VM, CLACKSON T, LODDE BM, MINESHIBA F, BAUM BJ. Rapamycin control of transgene expression from a single AAV vector in mouse salivary glands. Gene Ther 2006;13:187-190. [PubMed: 16177817]

WANG M, ORSINI C, CASANOVA D, MILLAN JL, MAHFOUDI A, THUILLIER V. MUSEAP, a novel reporter gene for the study of long-term gene expression in immunocompetent mice. Gene 2001;279:99-108. [PubMed: 11722850]

WEISS G, GOODNOUGH LT. Anemia of chronic disease. N Engl J Med 2005;352:1011-1023. [PubMed: 15758012]

WOLFF JA, LUDTKE JJ, ACSADI G, WILLIAMS P, JANI A. Long-term persistence of plasmid DNA and foreign gene expression in mouse muscle. Hum Mol Genet 1992;1:363-369. [PubMed: 1301910]

ZHANG G, LUDTKE JJ, THIOUDELLET C, KLEINPETER P, ANTONIOU M, HERWEIJER H, BRAUN S, WOLFF JA. Intraarterial delivery of naked plasmid DNA expressing full-length mouse dystrophin in the mdx mouse model of duchenne muscular dystrophy. Hum Gene Ther 2004;15:770782. [PubMed: 15319034] 


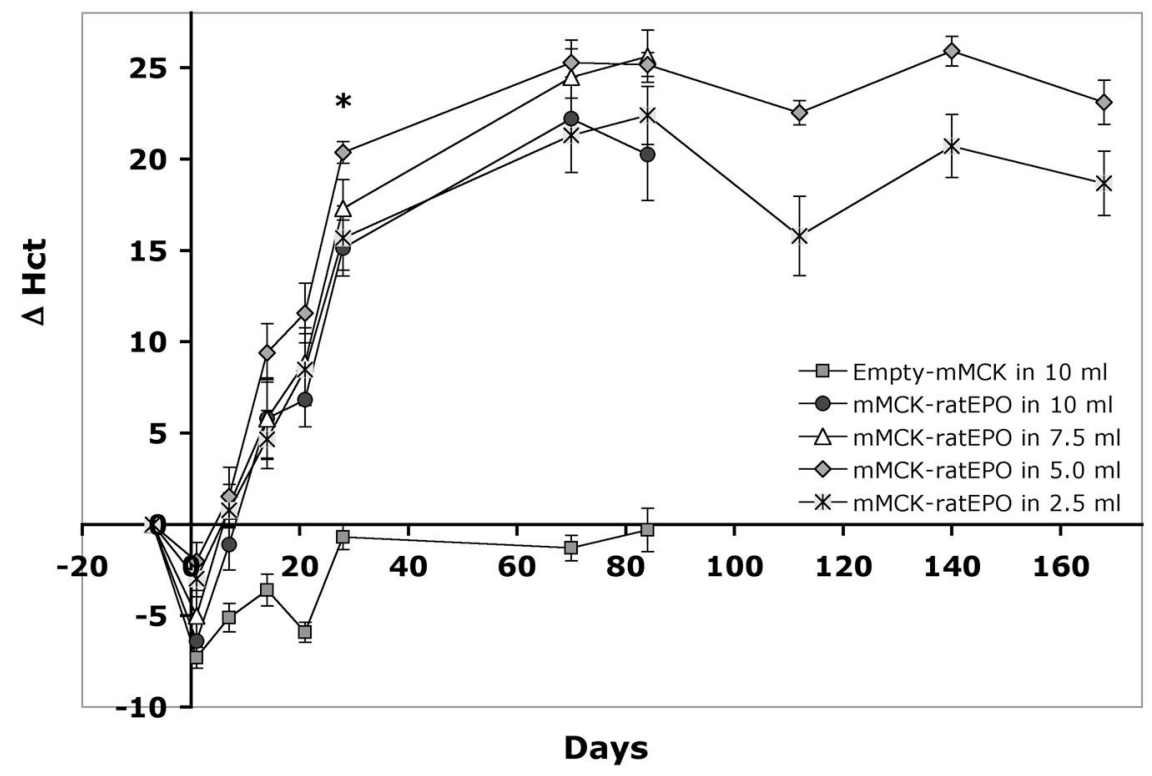

Figure 1. Injection volumes between 2.5 and $10 \mathrm{ml}$ are all suitable for EPO gene delivery into the skeletal muscle of adult rats

A constant amount $(500 \mu \mathrm{g})$ of mMCK-ratEPO pDNA was injected on day 0 into the hind limbs of adult Lewis rats in various volumes. The physiological effect of the expressed EPO was followed by analyzing the absolute changes in the animals' hematocrit ( $\Delta$ Hct) at various time points. Group averages and SEM are shown ( $\mathrm{n}=10$ animals per group). The asterisk marks the first time point (day 28) when significant differences between the 5 ml-injected group and the 10 or 2.5 ml-injected ones could be observed $(\mathrm{p}<0.05)$. While the 5 and 2.5 ml-injected groups remained significantly different across all time points $(\mathrm{p}=0.024)$, differences between the other EPO-injected groups did not reach statistical significance. 


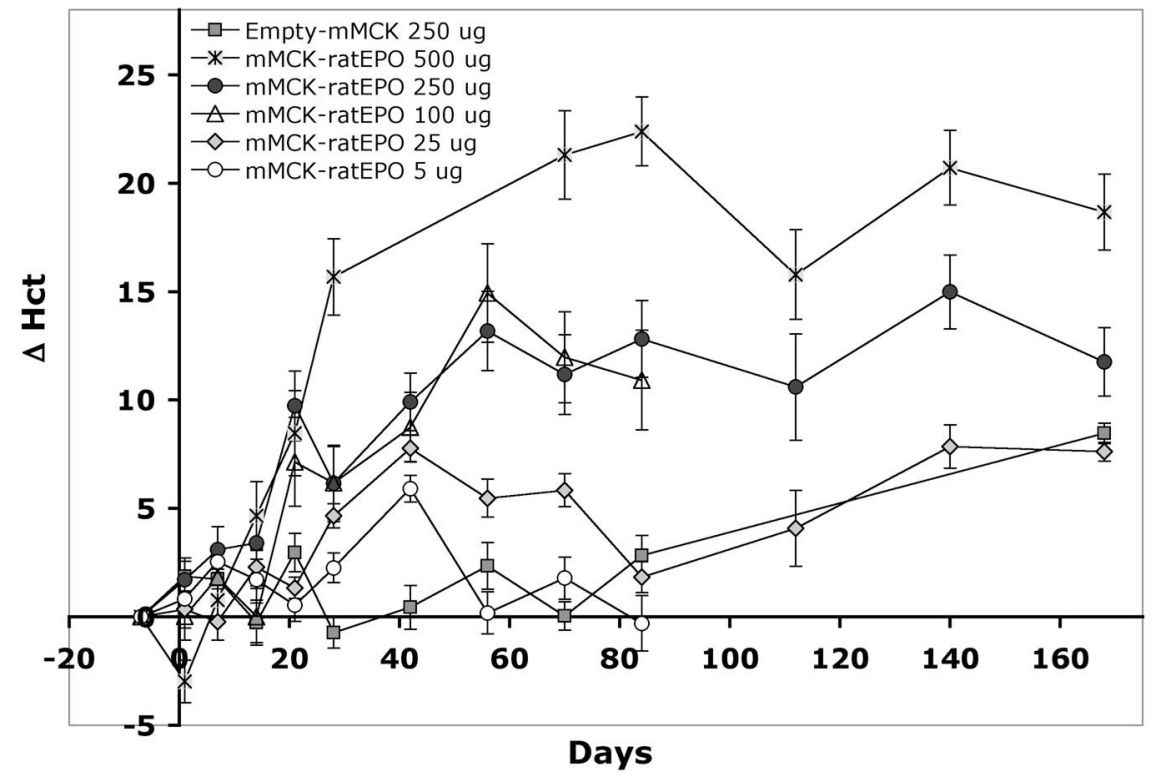

Figure 2. The physiological response of rats to EPO gene delivery is pDNA dose dependent The mMCK-ratEPO expression plasmid was delivered (on day 0) into adult Lewis rats using a low, $2.5 \mathrm{ml}$ injection volume and 5, 25, 100, 250 or $500 \mu \mathrm{g} / \mathrm{animal}$ pDNA dose. (Data for the $500 \mu \mathrm{g} / \mathrm{animal}$ curve are from the study shown on Figure 1.) The physiological effect of the expressed EPO was assessed by analyzing absolute changes in the animals' hematocrit ( $\Delta \mathrm{Hct}$ ) at various time points after delivery. Group averages and SEM are shown $(n=10$ animals per group). 

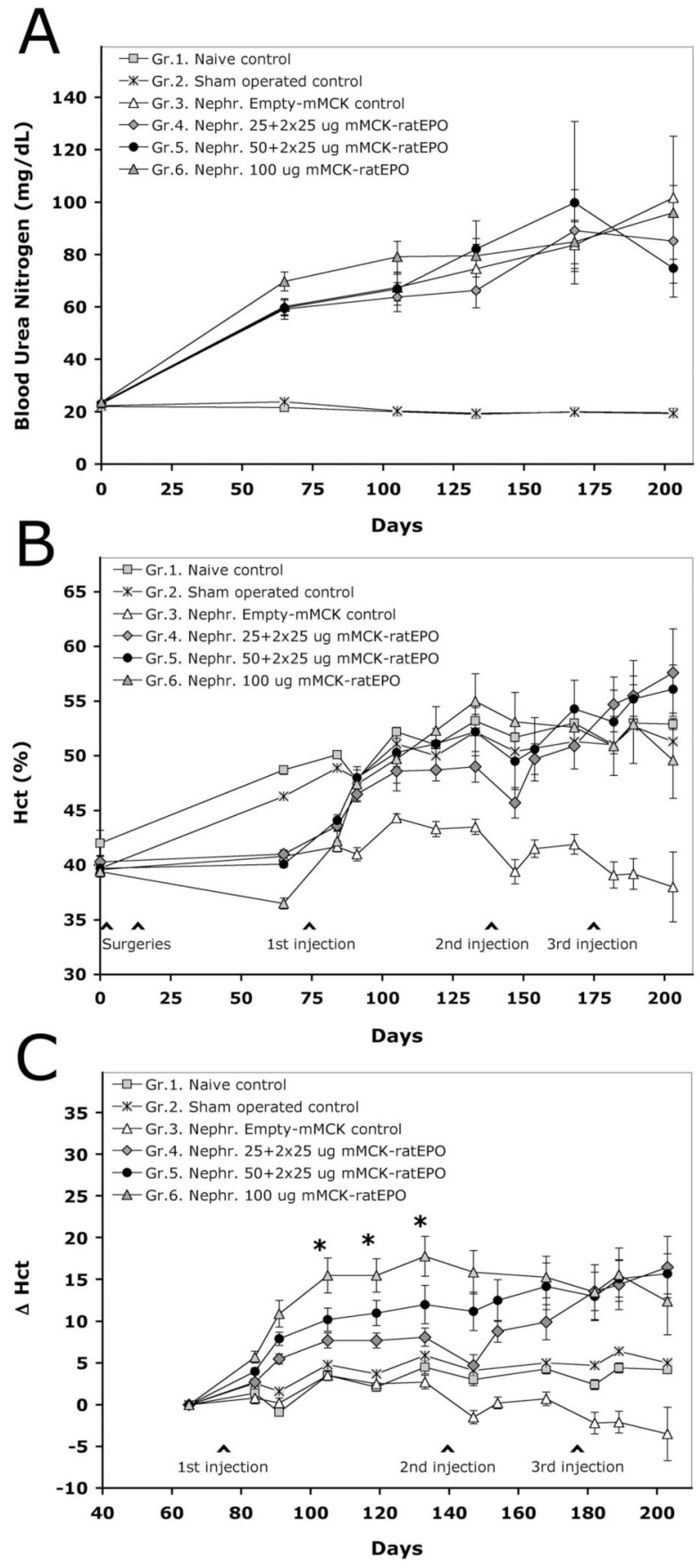

Figure 3. Correction of anemia in a rat disease model by the repeated, small-dose injections of mMCK-ratEPO

The anemia model was created by 5/6 nephrectomy, followed by the HLV delivery of either an empty control vector (Group 3), or the EPO-expressing mMCK-ratEPO pDNA (Groups 46 ). The naïve (Group 1) and sham-operated (Group 2) controls did not receive any pDNA. A. Blood urea nitrogen values $(\mathrm{mg} / \mathrm{dL})$. B. Hematocrit values $(\%)$. C. Each individual animals' pre-injection baseline hematocrit was subtracted from their hematocrit value at any later time point to plot the absolute change in their hematocrit $(\Delta \mathrm{Hct})$ resulted by gene delivery. Group averages and SEM values are shown. Initial number of animals in the groups: Gr.1. n=7; Gr. 2. $n=10 ; \mathrm{Gr} .3,4$ and $5 \mathrm{n}=11$; Gr.6. $\mathrm{n}=12$. The asterisks mark a 4-week period between days 
105-133, when $\Delta$ Hct values in all three EPO-injected groups were significantly different from the control groups (at least $\mathrm{p}<0.05$ ) and when Gr.4. and Gr.5. were also significantly different from Gr.6. $(\mathrm{p}<0.05)$. While all three EPO-treated groups remained significantly different from the controls for the rest of the study, differences between the three EPO-injected groups diminished after delivering additional mMCK-ratEPO doses. 

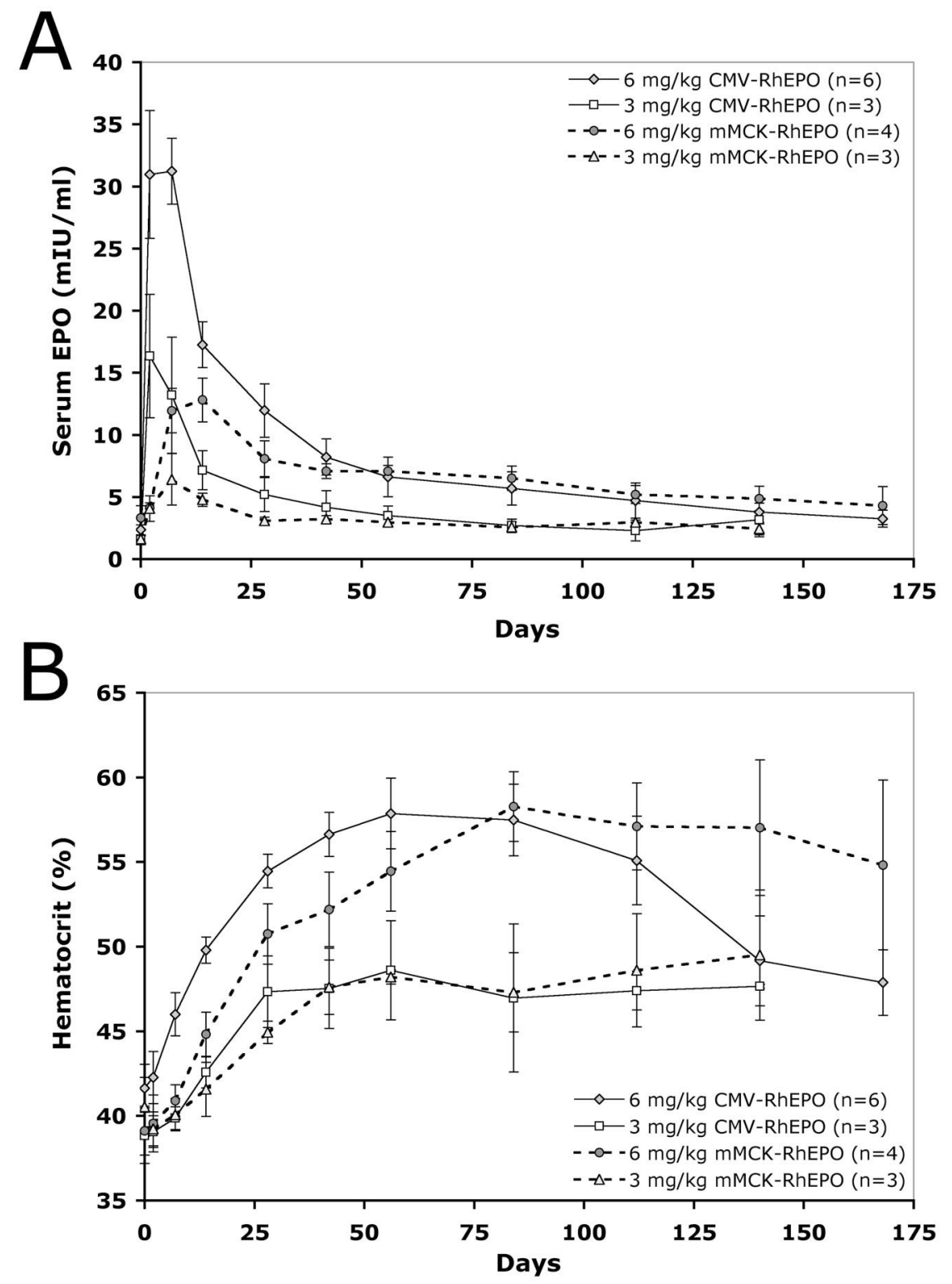

Figure 4. The level of EPO expression and its physiological effect in rhesus monkeys is dosedependent

The animals were injected either with the CMV-RhEPO or mMCK-RhEPO construct at $6 \mathrm{mg} /$ $\mathrm{kg}$ or $3 \mathrm{mg} / \mathrm{kg}$ dose. Panel A shows serum EPO concentrations at various time points while panel $\mathbf{B}$ illustrates the resulting physiological response leading to elevated hematocrit values. Group averages and SEM values are shown. 

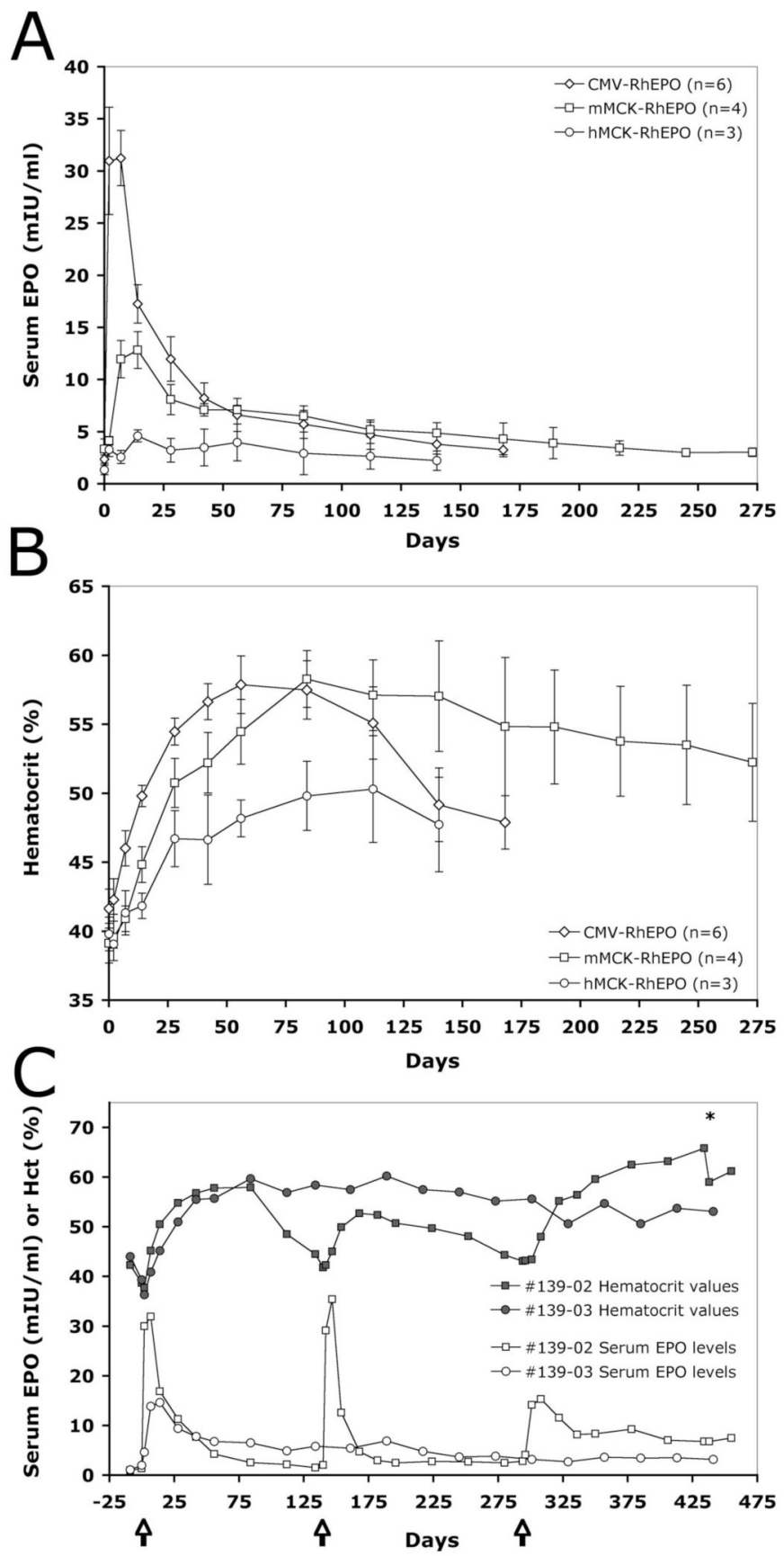

Figure 5. The kinetics of serum EPO changes and of the ensuing physiological response are promoter-dependent

On day 0 animals were injected either with the CMV-RhEPO, mMCK-RhEPO or hMCKRhEPO construct at $6 \mathrm{mg} / \mathrm{kg}$ dose. Serum EPO levels (A) and hematocrit values (B) were determined at various time points. The average and the SEM of results from 3-6 injections per condition are shown. Panel $\mathbf{C}$ shows both the serum EPO concentrations and the hematocrit values for two individual animals injected either with a single $6 \mathrm{mg} / \mathrm{kg}$ dose of $\mathrm{mMCK}-\mathrm{RhEPO}$ (animal \#139-03) or with two identical, repeated $6 \mathrm{mg} / \mathrm{kg}$ doses of CMV-RhEPO on day 0 and day 140, followed by a third delivery of $6 \mathrm{mg} / \mathrm{kg}$ of mMCK-RhEPO on day 294 (animal 
\#139-02). Arrows mark the time of injections. The asterisk marks the time when therapeutic phlebotomy was performed on animal \#139-02 to lower the hematocrit below 60\%. 

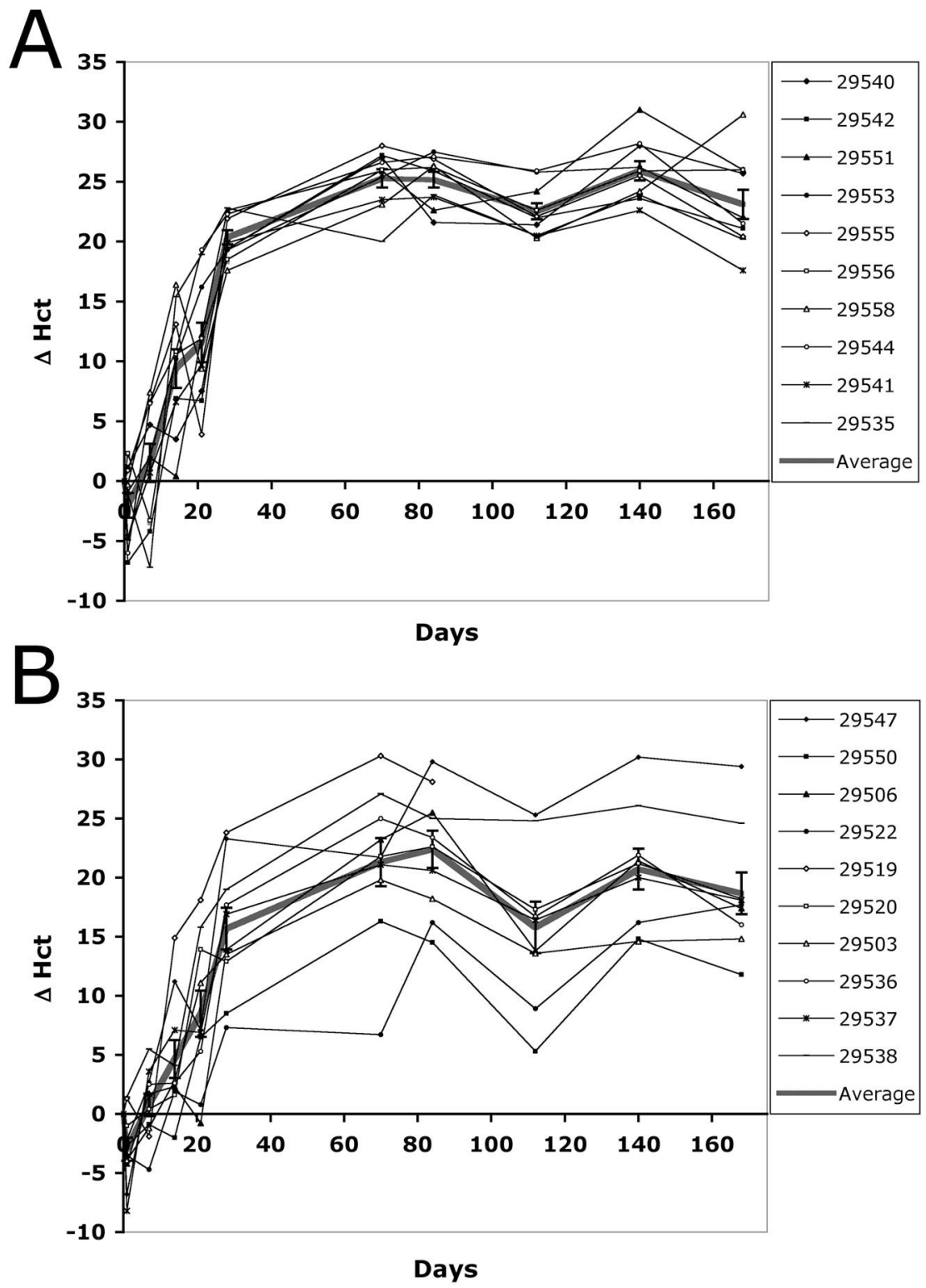

Figure 6. The variability of the physiological response after HLV delivery of EPO-expressing naked pDNA increases in rats when sub-optimal injection volumes are used

Adult Lewis rats were injected with $500 \mu \mathrm{g}$ mMCK-ratEPO pDNA in either $5 \mathrm{ml}$ (A) or 2.5 $\mathrm{ml}$ (B) NSS. Changes in absolute Hct values ( $\Delta \mathrm{Hct}$ ) for the 10 individual animals in each group are shown as well as the Average and SEM of the groups. In the legend, the animals are referred to by their ID numbers. 

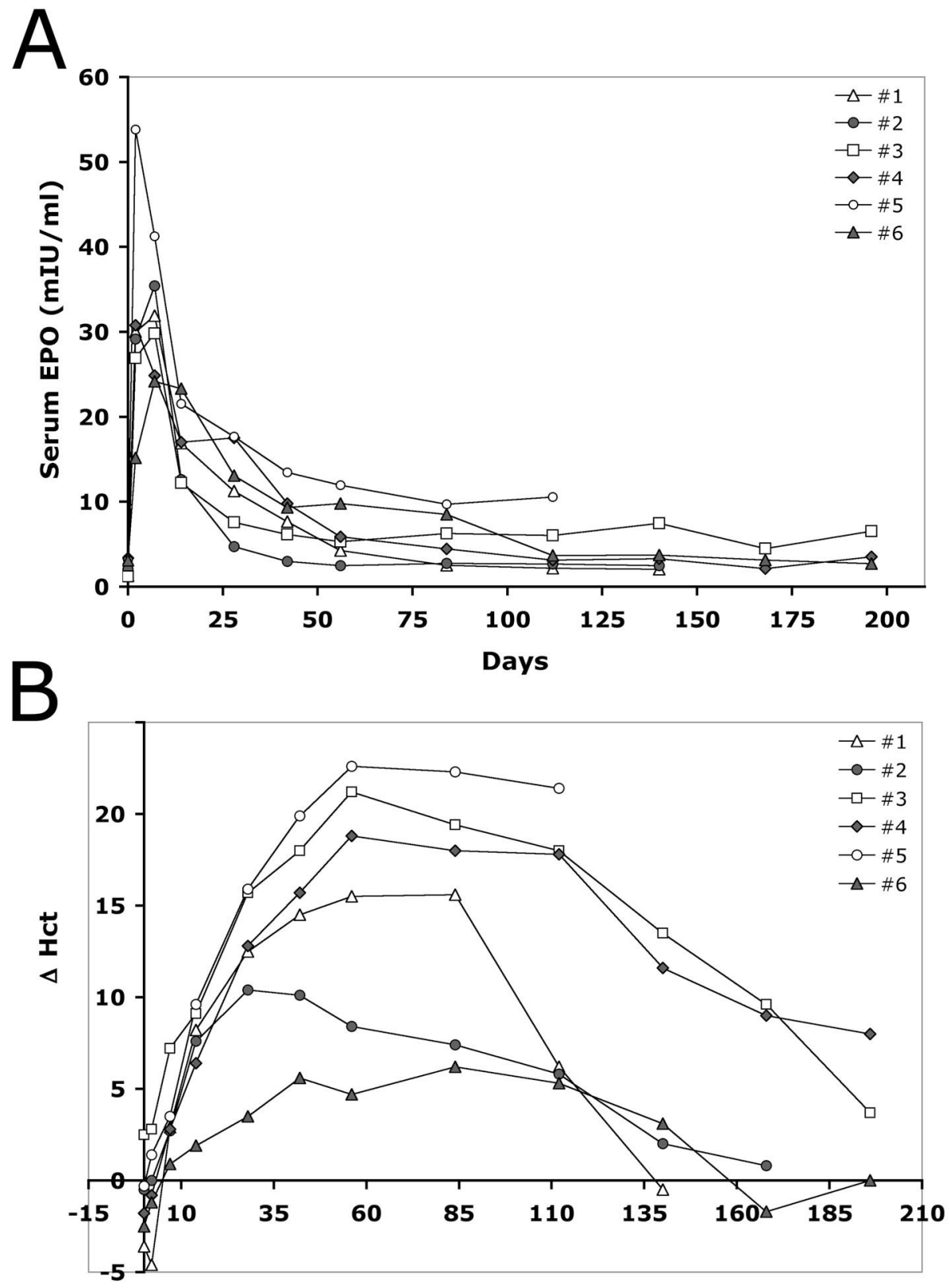

Days

Figure 7. Variability of EPO expression and the physiological response of individual rhesus monkeys after identical HLV delivery of pCMV-RhEPO

Six identical injections were performed on male rhesus monkeys using $6 \mathrm{mg} / \mathrm{kg}$ pDNA dose. A. Serum EPO concentrations $(\mathrm{mIU} / \mathrm{ml})$. B. Changes in hematocrit values $(\Delta \mathrm{Hct})$. 


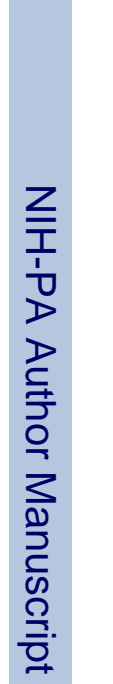

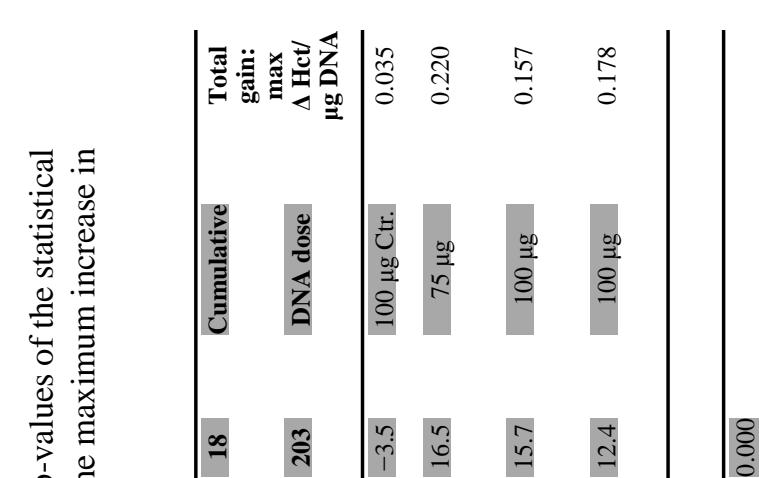

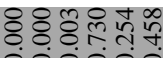

एक

言 뜬

言言

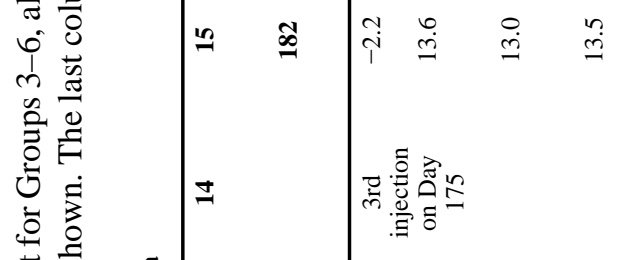

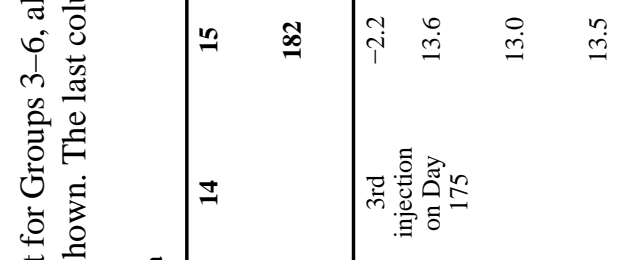

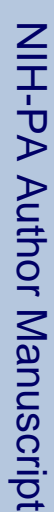

음

응

每

音

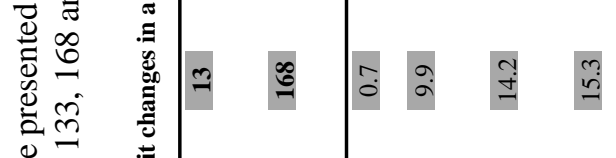

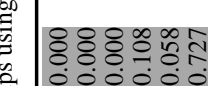

总

过

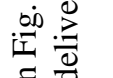

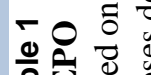

西

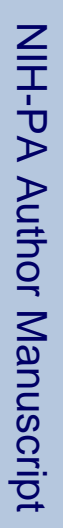

อ

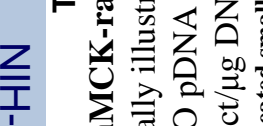

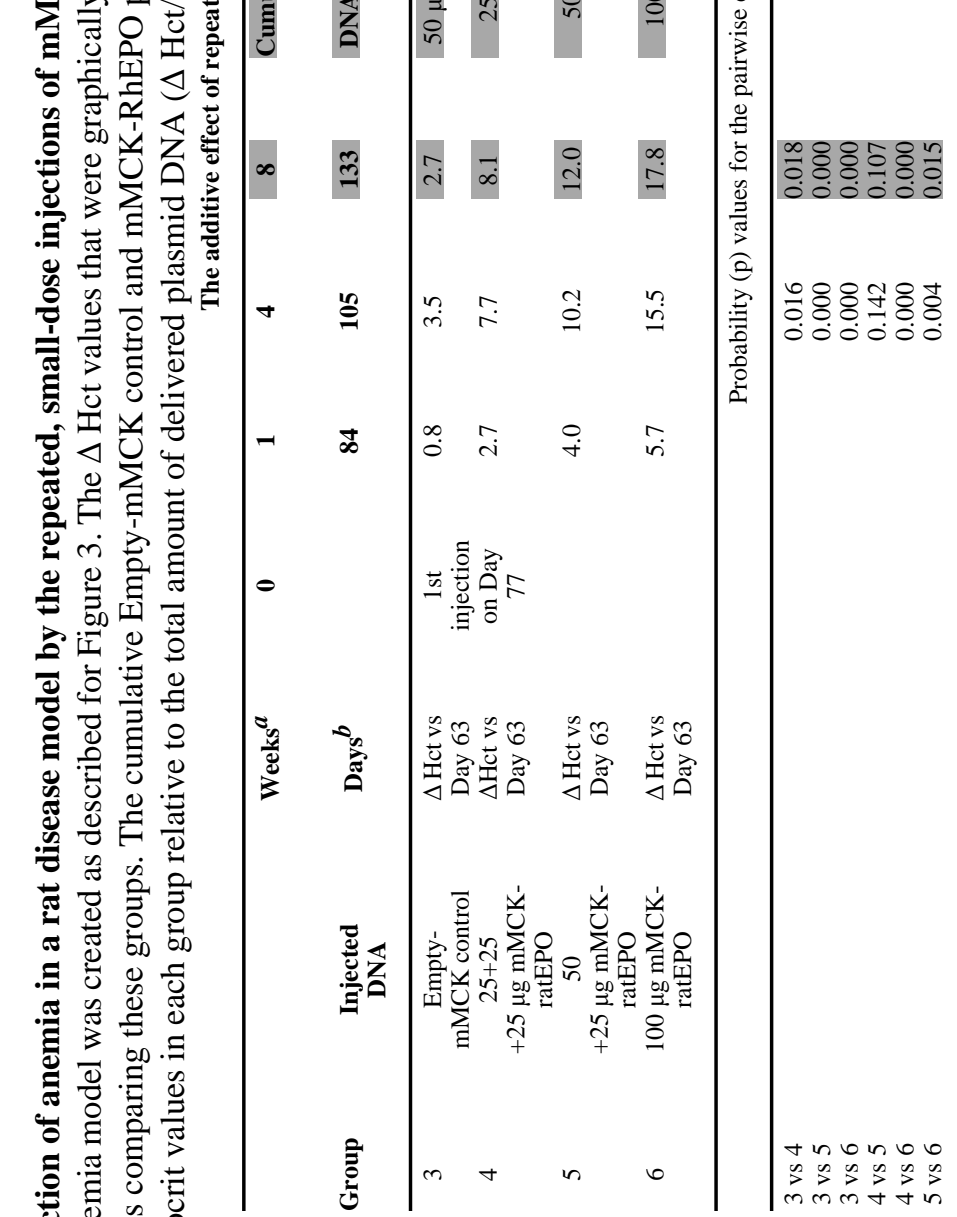

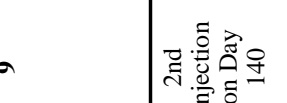


Table 2

The results of HLV injections in rat are reproducible

Two identical sets of injections ( $n=5$ animals per group) were performed by two equally experienced animal technicians. $500 \mu \mathrm{g}$ mMCK-ratEPO pDNA was injected into the saphenous vein of adult Lewis rats using various injection volumes. The hematocrit values were compared between the groups 42 days post-injection using ANOVA. None of the parallel groups of this study showed significant differences neither at this, nor at any other time point.

\begin{tabular}{|c|c|r|r|r|}
\hline \multirow{2}{*}{$500 \mu \mathrm{g}$ mMCK-ratEPO injected in volume: } & \multicolumn{2}{|c|}{ Investigator A } & \multicolumn{2}{c|}{ Investigator B } \\
\cline { 2 - 5 } & Average Hct & SEM & Average Hct & SEM \\
\hline $10 \mathrm{ml}$ & 69.06 & 4.92 & 68.35 & 1.8 \\
\hline $7.5 \mathrm{ml}$ & 73.32 & 2.32 & 73.00 & 1.07 \\
\hline $5.0 \mathrm{ml}$ & 75.08 & 0.97 & 74.92 & 1.34 \\
\hline $2.5 \mathrm{ml}$ & 69.66 & 2.35 & 70.28 & 2.18 \\
\hline
\end{tabular}

